\title{
Fast hydrodynamic model for medium- and long-term dispersion in seawater in the English Channel and southern North Sea, qualitative and quantitative validation by radionuclide tracers
}

\author{
P. Bailly du Bois ${ }^{a^{*}}$ and F. Dumas ${ }^{b}$ \\ aLaboratoire de Radioécologie de Cherbourg-Octeville, Institut de Radioprotection et de Sûreté Nucléaire (IRSN), \\ Direction de l'Environnement et de l'Intervention, rue Max Pol Fouchet, B.P. 10, 50130 Octeville, France \\ ${ }^{b}$ Institut Français de Recherches pour l'Exploitation de la Mer, Service des Applications Opérationnelles, B.P. 70, \\ 29280 Plouzané, France \\ *: Corresponding author : Tel.: +33 02330141 05/00; fax: +33 0233014130 pascal.bailly-du-bois@irsn.fr
}

\begin{abstract}
The database for medium- and long-term model validation using $125 \mathrm{Sb}$ released by the La Hague reprocessing plant includes 1400 measurements performed between 1987 and 1994 in the English Channel and the North Sea and data for each release since 1982. Antimony-125 has a conservative behaviour in water masses over a period of several years. These data can be used qualitatively and quantitatively to compare the measured concentrations with the calculated ones and quantities of tracers. Tritium measurements are also available for model calibration.

A two-dimensional hydrodynamic model has been developed to allow repetitive long-term simulations. This model uses a database of residual tidal currents calculated using the Lagrangian barycentric method [Salomon, J.C., Guéguéniat, P., Orbi, A., Baron, Y., 1988. A Lagrangian model for long-term tidally induced transport and mixing. Verification by artificial radionuclide concentrations. In: Guary, J.C., Guéguéniat, P., Pentreath, R.J. (Eds.), Radionuclides: A Tool for Oceanography, Cherbourg 1-5 June, 1987. Elsevier Applied Science Publishers, London, New York, pp. 384-394]. The area covered by the model includes the English Channel, the southern North Sea and the Irish Sea with a mesh size of $1 \mathrm{~km}$.

The main adjustment parameters of this model are the sources of wind data used and the calculation method for evaluating wind stress at the sea surface. With these parameters, the fluxes of radionuclides and water masses in the English Channel and the North Sea were balanced for the whole period of field measurements (1987-1994). The correlation factor between individual measurements in seawater and calculation results is 0.88 with an average error of $\pm 54 \%$, the error attributable to the measurement process being $15 \%$ on average. The mean flux through the Dover Strait is $126,000 \mathrm{~m} 3 \mathrm{~s}-1$, close from the one obtained from previous studies [Salomon, J.C., Breton, M., Guéguéniat, P. 1993. Computed residual flow through the Dover Strait. Oceanologica Acta 16 (56) (1993) 449-455; Bailly du Bois, P., Salomon, J.C., Gandon, R., Guéguéniat, P. 1995. A quantitative estimate of English Channel water fluxes into the North Sea from 1987 to 1992 based on radiotracer distribution. Journal of Marine Systems 6 (5-6) (1995) 457-481; Prandle, D., Ballard, G., Flatt, D., Harrison, A.J., Jones, S.E. Knight, P.J., Loch, S. McManus, J. Player, R. Tappin, A., 1996. Combining modelling and monitoring to determine fluxes of water, dissolved and particulate metals through the Dover Strait. Continental Shelf Research 16 (2) (1996) 237-257]. This model appears as a robust tool for modelling long-term dispersion at a low computation cost (it takes less than $1 \mathrm{~h}$ to simulate one year on a personal computer). It could forecast consequences of controlled or accidental releases of soluble substances in seawater under realistic conditions or calculate water masses fluxes and transit times.
\end{abstract}

Keywords: Modelling; Calibration; Wind stress; Radioactive tracer; Sb-125; Tritium; European continental shelf; English Channel; North Sea 


\section{Table of contents}

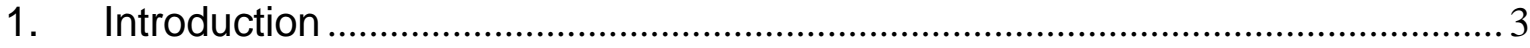

2. Hydrodynamic model .................................................................................. 4

2.1. Method4

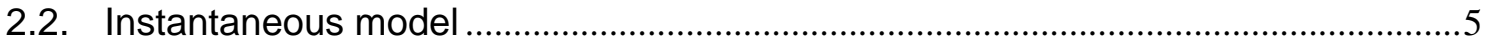

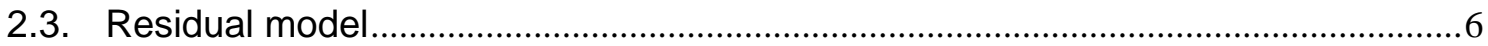

2.3.1. Tide representation ......................................................................................

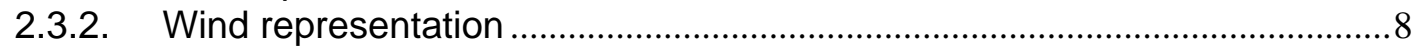

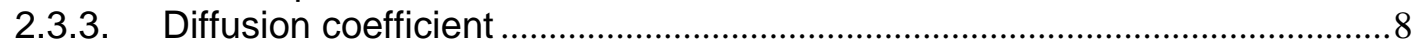

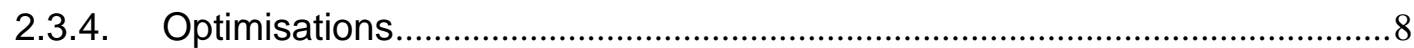

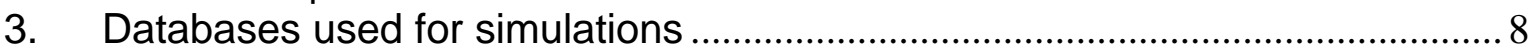

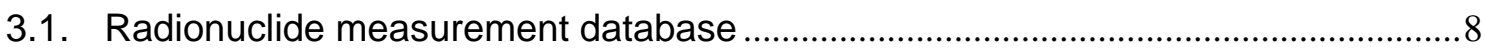

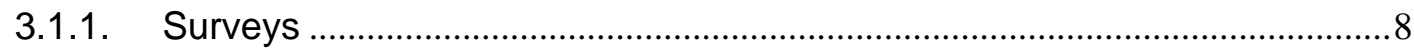

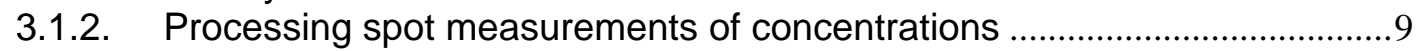

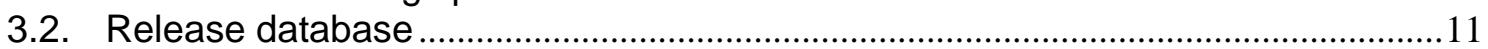

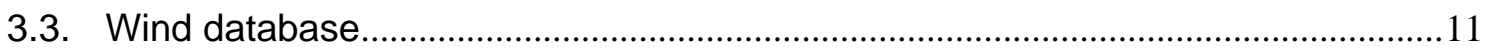

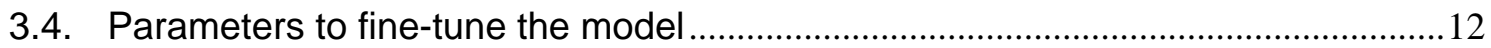

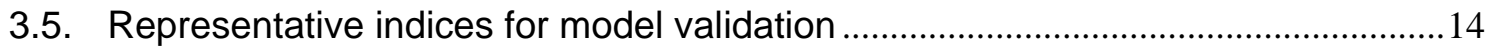

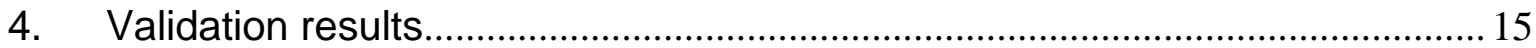

4.1. Comparison of model/measurements without calibration (reference run) .............15

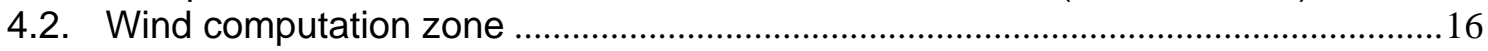

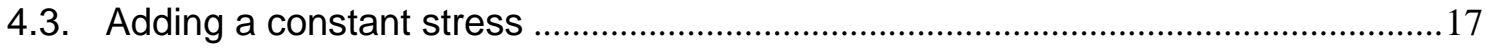

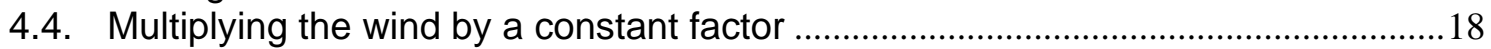

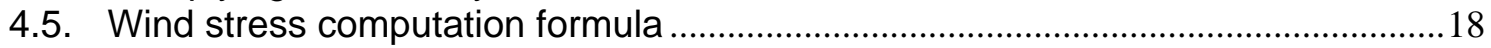

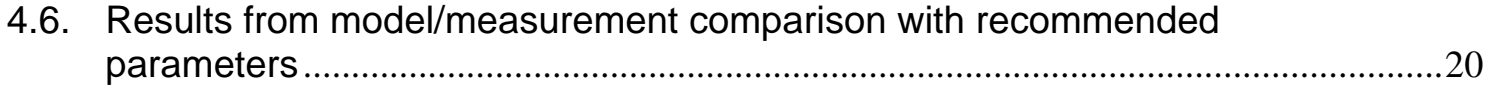

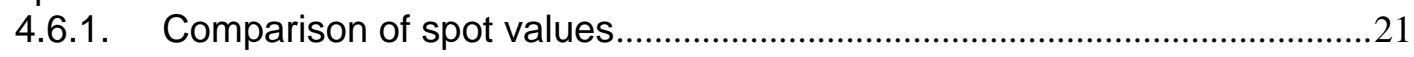

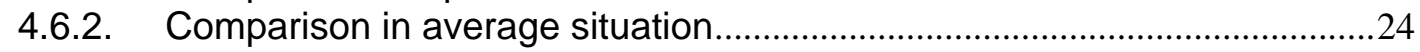

4.7. Comparing model/measurements, other radionuclides and other surveys ...........24

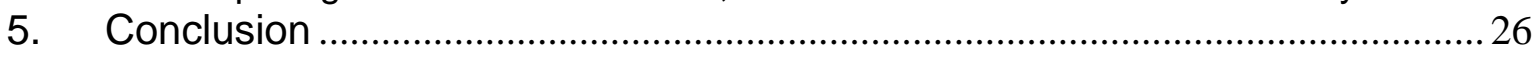

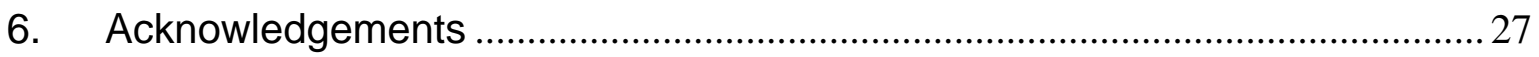

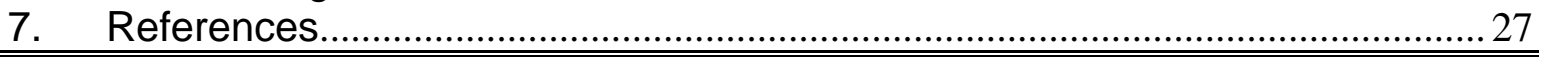




\section{INTRODUCTION}

Great progress has been made in hydrodynamic modelling of water-mass movement, and advances in computing have enabled the simulation of long-term physical transport and dispersion of waters on the scale of the English Channel and North Sea. These models make it possible to predict the consequences of manmade pollutant discharges into the marine environment under realistic conditions of release, weather or tide. They are increasingly vital tools for marine ecosystem management, for both managed and accidental releases.

In particular, the "Lagrangian barycentric" method, developed by J.C. Salomon (Salomon et al, 1988, Orbi and Salomon 1988), can calculate the movement and dilution of chemical substances dissolved in sea water over long time scales (several years) and large spatial scales (thousand kilometres). Observed concentrations represent the result of substances transported in seawater over distances of tens to hundreds of kilometres, over periods of weeks to months and years; these models allow direct comparison between the soluble substance concentrations obtained through simulations and measurements made in-situ.

Validation of accurate hydrodynamic models requires field data of comparable accuracy and coverage. The ideal tracer would better show conservative behaviour in the water mass, i.e., neither fixed by environmental components (sediment, living species) nor modified during its stay in seawater, and when subsequently diluted. It must be measurable several hundred or thousand kilometres from its input point. It must have only one or a few origins and the discharge conditions and flow must be well known.

Artificial radionuclides released by nuclear fuel reprocessing plants fully meet these specifications if their half-life is long enough compared to the transit-times in the studied area (over one year). They can also be measured in very low concentrations in seawater (concentrations 40,000 times lower than natural radioactivity of seawater for gamma-emitters).

The general circulation of water masses in the Channel and the North Sea has been clarified by measuring soluble radionuclides (Kautsky, 1988; Nies and Wedekind, 1988; Bailly du Bois et al, 1993 - 2002; Guéguéniat et al, 1994 - 1997; Kershaw and Baxter, 1995; and Hermann et al, 1995). The general pattern of these displacements is shown in Figure 1 (Bailly du Bois et al, 2002).

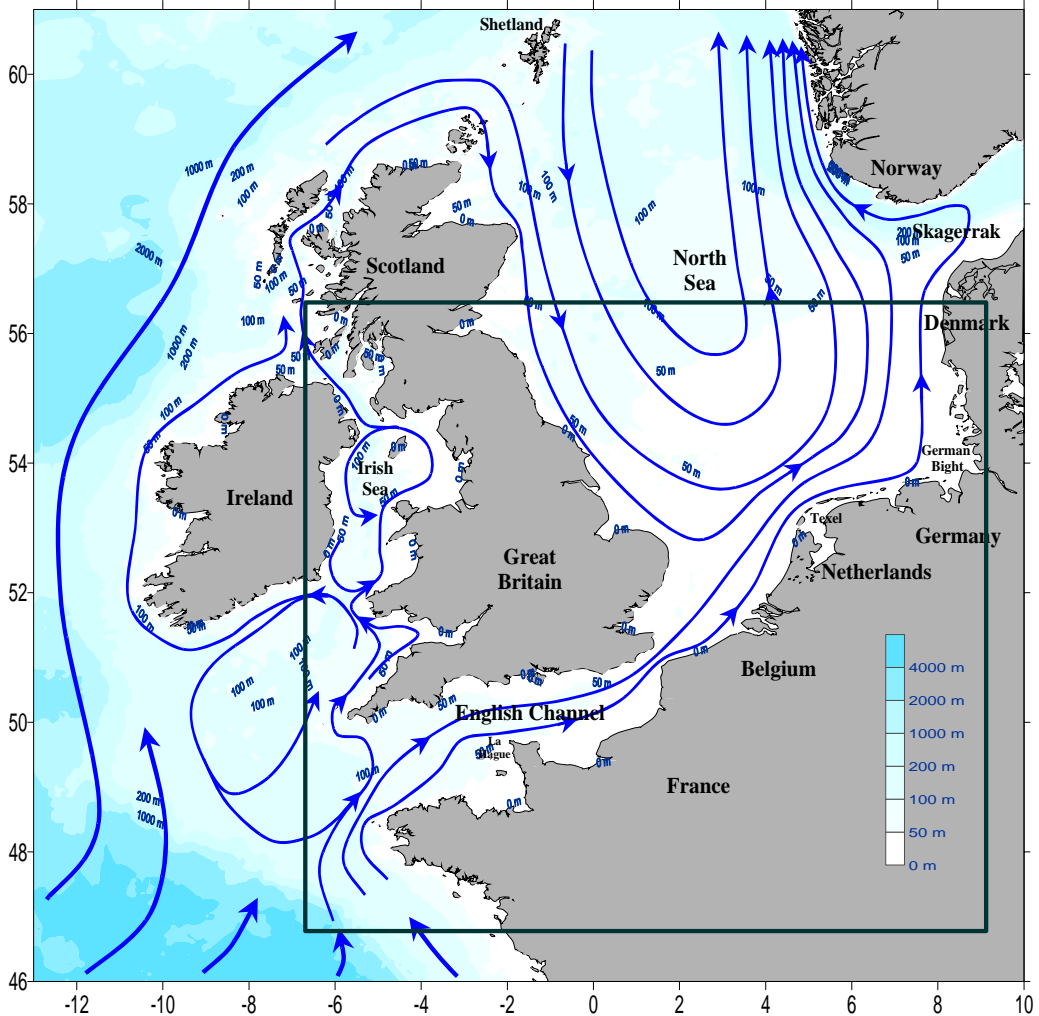

Figure $1 \quad$ Simplified scheme of water masses general circulation in north-western European seas (Bailly du Bois et al, 2002), and the area covered by the model

Since 1960, large-scale studies have chiefly concerned caesium-137, a radionuclide mainly originating from the nuclear fuel reprocessing plant at Sellafield on the Irish Sea (Kautsky, 1988; Dahlgaard et al., 1991; Kershaw and Baxter, 1995; Povinec et al, 2003). Other tracers, namely caesium-134, strontium-90 and technetium-99, have been used to monitor the transport of water masses. Since 1987, the IRSN- Cherbourg laboratory for radioecological studies (LRC) has undertaken oceanographic surveys covering the English 
Channel, and measuring radionuclides specific to releases from the La Hague nuclear fuel reprocessing plant. These radionuclides are antimony-125, ruthenium-106 and, more recently, tritium.

Radioactivity measurements have been combined with data concerning currents, salinity and temperature in order to characterise the overall circulation pattern of water masses in the North Sea and to evaluate the renewal time and flow parameters of these water masses by qualitatively and quantitatively linking the activity distribution measured at sea with the variation of industrial releases over time (Bailly du Bois et al., 1993 - 1998).

Results obtained from previous studies involving residual current models have generally shown good agreement between calculated and measured results. The average radionuclide distribution measured and observed has been well reproduced in the English Channel and the North Sea (Salomon et al., 1991 - 1995; Breton and Salomon, 1995; Bailly du Bois et al, 1995, 1999). However, significant differences were observed between the calculated and measured tagged plumes at a given date (Bailly du Bois et al, 1995 compared to Breton and Salomon, 1995), computed concentrations overestimate concentration of $46 \%$ in average (Breton and Salomon, 1995) and budget of radionuclides quantities were not balanced (Bailly du Bois et al, 1995).

This study was designed to specify the fine-tuning parameters of hydrodynamic models, particularly meteorological forcing. This was done in order to reproduce, as faithfully as possible, the soluble radiotracer distributions and quantities observed in the Channel and the North Sea at any given date. The objective is to define a unique set of parameters for simulating the dispersion of dissolved substances in seawater under realistic wind and tide conditions, on a scale of months and years in the Channel and the North Sea.

The model developed must fulfil the following objectives:

- Simulate dispersion in seawater in the English Channel and the North Sea under realistic conditions (real releases, tide, meteorological forcing);

- Reconstitute past controlled release dispersion from nuclear fuel reprocessing plants;

- Qualitatively and quantitatively compare in-situ measurements with simulation results;

- Forecast consequences of controlled or accidental releases of soluble substances in seawater.

\section{OVERVIEW}

The hydrodynamic models used in the study are described in the second section. The third section deals with the measurements and the database built for tuning and validating the residual model. Lastly, the fourth section discusses the actual tuning and validation results.

\section{HYDRODYNAMIC MODEL}

\subsection{METHOD}

Although the hydrodynamic models which fully solve the fluid dynamics equations (i.e. Navier-Stokes or Saint-Venant equations) provide better simulations of the physical processes, they require significant computing time. The model used in this study uses tidal residual currents applying the method developed by J.C. Salomon and A. Orbi. It is described at length in Orbi and Salomon (1988), Salomon and Breton (1993) and Breton and Salomon (1995). It is a way to filter out the tidal signal from the velocity field to obtain the low-frequency signal responsible for the long-term transport.

This type of model reduces computing time by a factor of 1000 compared to an instantaneous current model with a similar domain and resolution. The model developed is a 2D model with spherical coordinates based on the hypothesis that the flow is nearly homogenous over the vertical direction: it is well suited to simulate barotropic flows such as tidally dominated ones. The mesh size is close to one kilometre over the entire model domain, which has one million computational meshes. The model uses a database of tidal residual currents that have been pre-computed for representative wind (constant in time and uniform in space) and tide conditions. It interpolates the data according to true tide and wind conditions at the moment of the simulation. As the instantaneous tidal currents are not taken into account, the model results could be used only when tidal residual currents have a larger extent than tidal instantaneous currents. In the centre of the English Channel where the tidal currents have the larger extend, this condition is always obtained one week after a release, and at a distance of more than $30 \mathrm{~km}$ from the outflow point (see Figure 2). So the model can only be used one week after a release, and at a distance of more than $30 \mathrm{~km}$ from the outflow point. This computation mode provides realistic simulations of radionuclide dispersion over several years (Breton 1995). Since the waters are shallow in the English Channel and North Sea (depths less than 100 metres, or even $50 \mathrm{~m}$ in the eastern Channel or the southern North Sea), the turbulence related to tidal currents brings about rapid mixing of the entire water column. Pingree and Griffiths (1978) and Nihoul (1980) showed that vertical mixing is obtained rapidly along the coasts of the English Channel, South of the North Sea, and Irish Sea, and east of $3^{\circ} \mathrm{W}$ in the English Channel and South of $53^{\circ} \mathrm{N}$ in the North Sea. For source-terms located in theses 
area, the dispersion of soluble substances on time scales of over a week in a macrotidal environment can then generally be modelled simply using such 2D models.

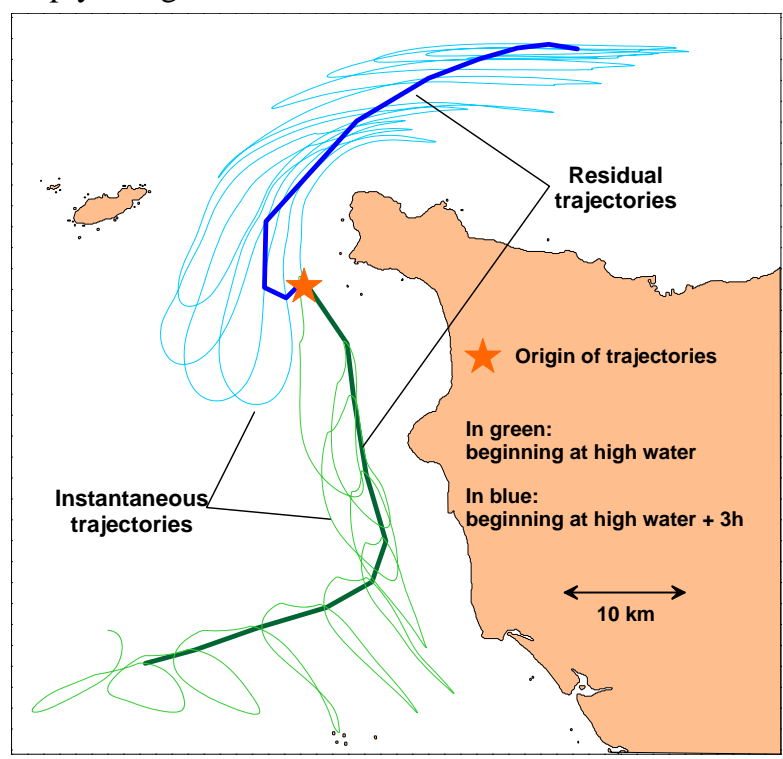
Figure 2 Instantaneous and Lagrangian (in bold) trajectories of drifting buoys near Cape La
Hague, central English Channel

Simulation of the trajectories of 2 drifting buoys released 3 hours apart in Spring tide The bold lines connect the points of trajectories at one tidal cycle apart $(12 \mathrm{~h} 24 \mathrm{mn})$. The simulated period lasts 5 days

\subsection{INSTANTANEOUS MODEL}

The tool providing the characteristics of tidal residual currents over the entire domain is a numerical model solving the Saint-Venant equations (i.e. vertically integrated Navier-Stokes equations). The computational domain was discretised using finite differences on the Arakawa C-grid (Arakawa and Lamb, 1977). The numerical scheme used is derived from the ADI or Alternate Direction Implicit integration method, and incorporates wetting and drying.

This model is driven at the open ocean boundaries by the free surface elevations, which are computed using Schwiderski's harmonic components atlas (1983). The tidal spectrum is reduced to the M2 component. Weak open boundary conditions are prescribed for the velocity. The large domain model's boundaries were pushed back beyond the continental margin (more than one external Rossby deformation radius) so that the wind would have very little effect on the free surface gradients.

The bottom boundary conditions, which correspond to the friction from water displacement on the seabed, are set with a Strickler coefficient formulation. The surface boundary conditions correspond to the frictional force of wind on the sea. The surface tensor is expressed by its two components $\tau_{x}$ and $\tau_{y}$, and can be formulated as follows:

$$
\left\{\begin{array}{l}
\tau_{\mathrm{x}}=\rho_{\mathrm{a}} \mathrm{Cd}_{\mathrm{x}}\|\overrightarrow{\mathrm{W}}\| \\
\tau_{\mathrm{y}}=\rho_{\mathrm{a}} \mathrm{Cd}_{\mathrm{y}}\|\overrightarrow{\mathrm{W}}\|
\end{array}\right.
$$

$\tau_{\mathrm{x}}, \tau_{\mathrm{y}}$ : wind stress components in N.m ${ }^{-2}$ along $\mathrm{x}$ and $\mathrm{y}$ (East-West and North-South) axes.

$\mathrm{W}_{\mathrm{x}}, \mathrm{W}_{\mathrm{y}}$ : wind speed components at $10 \mathrm{~m}$ in $\mathrm{m} . \mathrm{s}^{-1}$ along $\mathrm{x}$ and $\mathrm{y}$ (East-West and North-South) axes.

$\|\overrightarrow{\mathrm{W}}\|$ : wind vector module at $10 \mathrm{~m}$

$\rho_{\mathrm{a}}$ : $\quad$ air density.

$\mathrm{C}_{\mathrm{d}}$ : drag coefficient $\left(0.0015 \mathrm{~m}^{2} . \mathrm{s}^{-1}\right.$ by default, see 3.4 for other formulations)

The wind conditions for simplification sake's are stationary and homogenous; they are chosen in order to statistically representing the main observable meteorological situations. For each of the eight sectors of the wind, the statistics, calculated from $\tau_{\mathrm{x}}, \tau_{\mathrm{y}}$ along the English Channel give the following results (Table 1). 


\begin{tabular}{|lc|c|}
\hline \multicolumn{2}{|c|}{ Wind direction } & \multicolumn{2}{|c|}{ Wind speed (m.s $\left.\mathbf{~}^{\mathbf{1}}\right)$} \\
\hline N & $\left(0^{\circ}\right)$ & 7.49 \\
\hline NW & $\left(45^{\circ}\right)$ & 9.77 \\
\hline W & $\left(90^{\circ}\right)$ & 11.4 \\
\hline SW & $\left(135^{\circ}\right)$ & 10.8 \\
\hline S & $\left(180^{\circ}\right)$ & 7.63 \\
\hline SE & $\left(225^{\circ}\right)$ & 7.19 \\
\hline E & $\left(270^{\circ}\right)$ & 9.02 \\
\hline NE & $\left(315^{\circ}\right)$ & 10.19 \\
\hline \multicolumn{2}{|c|}{ No wind } & 0 \\
\hline
\end{tabular}

\section{Table 1}

\section{Wind directions and speeds applied to compute the residual current database with an average tide}

Last, the main rivers were represented in the instantaneous model as having a flow rate equal to the climatological average over several years. Furthermore, removing the seasonal signal from the rivers flow is of little importance when looking at time scales longer than years and space scales larger than thousands of kilometres.

\subsection{RESIDUAL MODEL}

The residual model was designed to reproduce transport, dilution and decay phenomena over long time scales (ranging from a week to several years) and extensive spatial scales (from 30 to $1,000 \mathrm{~km}$ ). It is based on the hypothesis that the water column is homogeneous and that barotropic phenomena will prevail over baroclinic phenomena in dynamics. The following equation is solved in the residual model:

$$
\frac{\partial \mathrm{HC}}{\partial \mathrm{t}}+\frac{\partial\left(\mathrm{HUC}-\mathrm{HK} \frac{\partial \mathrm{C}}{\partial \mathrm{x}}\right)}{\partial \mathrm{x}}+\frac{\partial\left(\mathrm{HVC}-\mathrm{HK} \frac{\partial \mathrm{C}}{\partial \mathrm{y}}\right)}{\partial \mathrm{y}}-\frac{\operatorname{tg} \Phi}{\mathrm{R}}\left(\mathrm{HVC}-\mathrm{HK} \frac{\partial \mathrm{C}}{\partial \mathrm{y}}\right)+\alpha \mathrm{HC}+\mathrm{S}=0
$$

$\mathrm{H}$ : depth of water column.

C: $\quad$ concentration of dissolved species.

U, V: East-West and North-South speed components.

$\mathrm{K}$ : diffusion coefficient.

$\alpha$ : nuclear decay coefficient.

S: $\quad$ source term.

$\Phi$ : point's latitude.

$\mathrm{R}$ : $\quad$ earth's radius.

$\mathrm{H}, \mathrm{U}$ and $\mathrm{V}$ are low frequency hydrodynamic components computed with the instantaneous model. The depth of water was set everywhere at the average level of the parcel of water, i.e., the depth that the water would have, without the astronomical tide and meteorological forcing. The $\mathrm{U}$ and $\mathrm{V}$ components of the residual lagrangian current were computed and located at the barycentre of the tidal trajectories using the instantaneous model with the barycentric Lagrangian method (Orbi and Salomon, 1988) in nine wind situations (Table 1) and for an average tide.

The "Lagrangian barycentric" method is based on kinematic considerations which do not perfectly respect the bathymetry variations; it cannot guarantee the non-divergence of the velocity field obtained. The maximum of the divergence unbalanced is of the order of some percents, which is unacceptable for the purpose of long-term simulations. This unbalanced is cancelled by looking for the closest velocity fields (according a norm 2), which is exactly non-divergent. This is done by solving a problem of optimisation under linear constraints: $\min _{\operatorname{div}\left(\overline{H U_{\text {nondiv }}}=0\right.}\left\|\overrightarrow{U_{d i v}}-\overrightarrow{U_{\text {nondiv }}}\right\|^{2}$

Where:

H: mean water depth

$\mathrm{U}_{\text {div }}$ : residual divergent velocity fields

$\mathrm{U}_{\text {nondiv }}$ residual non-divergent velocity fields looked for

The following figures show the structure of the Lagrangian residual current fields with a southwesterly wind of $10.8 \mathrm{m.s} \mathrm{s}^{-1}$ (Figure 3, Figure 4). Trajectories of Channel currents were compared with the long-term current atlas published earlier (Salomon and Breton, 1993). Both model structures are in good agreement. On this synoptic scale, the improved resolution (one mile in the 1993 atlas and one kilometre for the present model) has not revealed any really novel structure. 


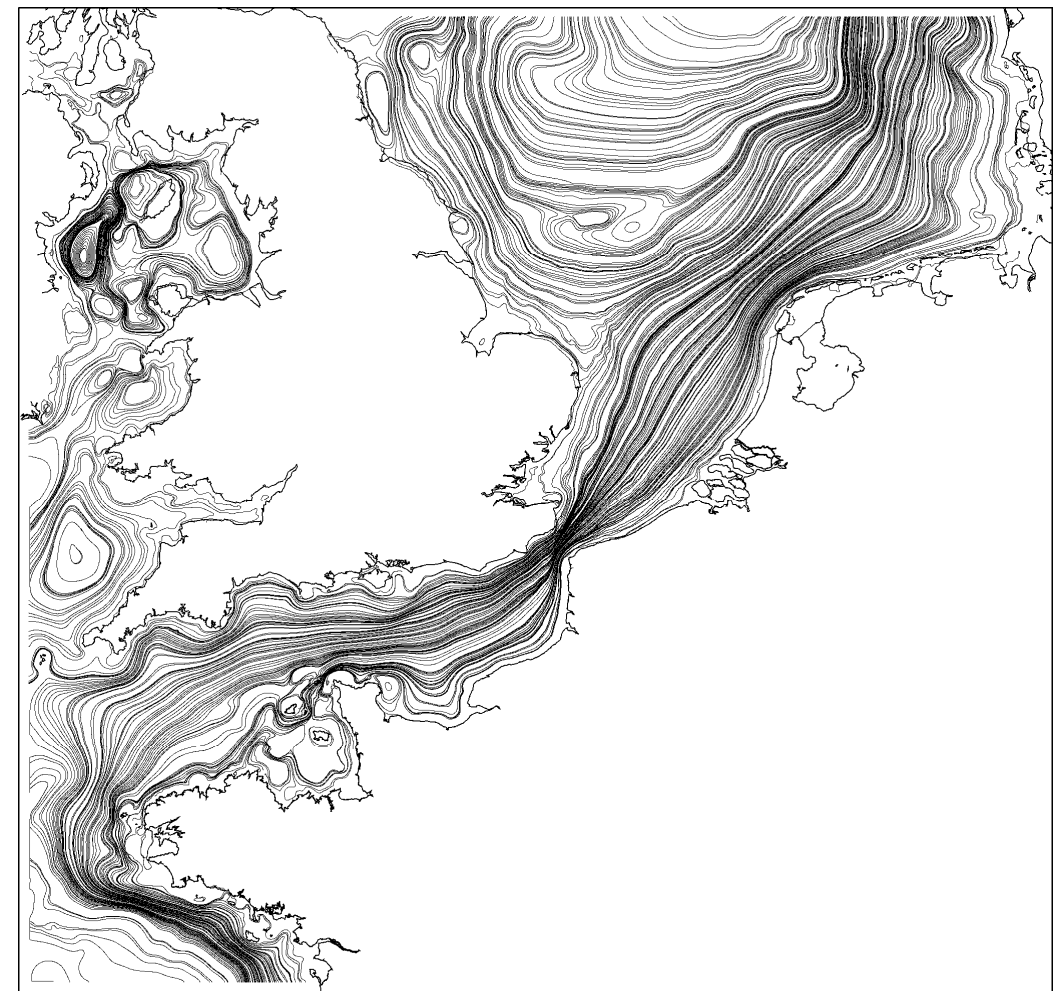

Figure $3 \quad$ Lagrangian residual trajectories, situation of wind from southwest sector $\left(\|\overrightarrow{\mathrm{W}}\|=10.8 \mathrm{~m} . \mathrm{s}^{-1}\right)$, general view.

\section{Figure 4}

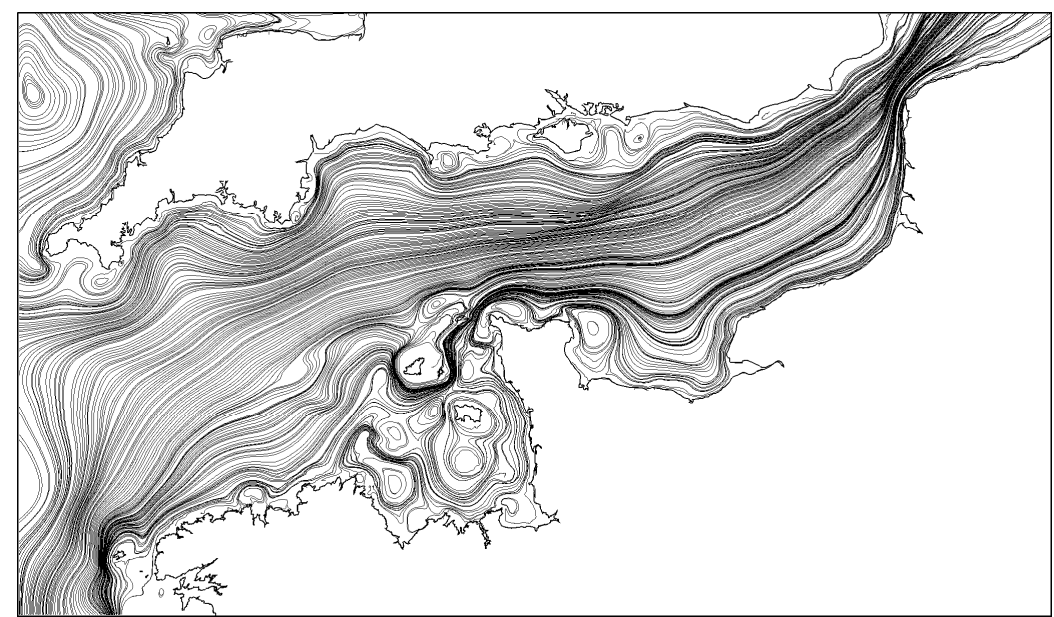

Lagrangian residual trajectories, situation of wind from southwest sector $\left(\|\overrightarrow{\mathrm{W}}\|=10.8 \mathrm{~m} \cdot \mathrm{s}^{-1}\right)$, detailed view of English Channel.

\subsubsection{Tide representation}

The French Hydrographic Service defined the magnitude of the tide of the day through the tide coefficient, which is the ratio of the semi-diurnal tidal amplitude over the mean spring equinox tidal amplitude in Brest. As along French coasts the tide is mostly semi-diurnal, the tide coefficient is a reliable way to assess the current tidal magnitude. The modulation of the residual current with respect to the tide coefficient is taken into account in the empirical formulation established by Salomon and Breton (1993):

$$
\overrightarrow{\mathrm{U}}_{\text {res }}=\overrightarrow{\mathrm{U}}_{0}+\left(\left(\frac{\mathrm{C}}{\mathrm{C}_{0}}\right)^{2.3}-1\right) \overrightarrow{\mathrm{U}}_{0}
$$

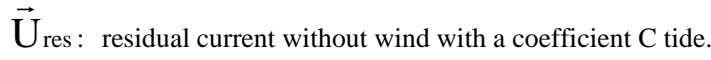

$\overrightarrow{\mathrm{U}}_{0}$ : residual current without wind with an average coefficient $\mathrm{C}_{0}$ tide.

C: $\quad$ tide coefficient $(20-120)$.

$\mathrm{C}_{0}$ : average tide coefficient (70). 
The numerical scheme used is an entirely explicit scheme whose stability criterion is the Courant number: $\Delta \mathrm{t} \leq \frac{\Delta \mathrm{x}}{\|\overrightarrow{\mathrm{U}}\|}$

\subsubsection{Wind representation}

In previous papers, Salomon accounts for the wind by calculating of residual currents each day, taking the average wind of the four previous days $(\mathrm{d}-\mathrm{d}-3)$. In order to better represent the time required for the model to reach equilibrium after a shift in the wind, the wind applied daily to the model is weighted as follows:

Model stress on day $\mathrm{D}=\left(\mathrm{WS}_{\mathrm{obs}} \mathrm{D}\right) \times \mathrm{x} 0.65+\left(\mathrm{WS}_{\mathrm{obs}} \mathrm{D}-1\right) \mathrm{x} 0.28+\left(\mathrm{WS}_{\mathrm{obs}} \mathrm{D}-2\right) \mathrm{x} 0.05+\left(\mathrm{WS}_{\mathrm{obs}} \mathrm{D}-3\right) \mathrm{x} 0.02$

Where $\mathrm{WS}_{\mathrm{obs}} \mathrm{D}=$ Wind stress observed on day $\mathrm{D}$

\subsubsection{Diffusion coefficient}

The instantaneous model is used to assess the horizontal diffusion coefficient, and especially its spatial variability, by computing $\frac{1}{T_{p}} \int_{\alpha}^{\alpha+T_{p}} H\|\vec{u}\| d t$ on every grid mesh (where $\mathrm{T}_{\mathrm{p}}$ is the $\mathrm{M}_{2}$ wave period). This quantity, which has the same dimension as a diffusion coefficient, can be used to calculate the diffusion coefficient by generalising the formula empirically established by Elder (1959) and Okubo (1971, 1974) for steady channel flows. It is formulated as follows: $K=\beta H\|\vec{u}\|$ (m.k.s.) where $\beta=0.25$.

This empirical formula was established for instantaneous flows. This means that it contains the entire spectrum of movements and therefore the advectives structures on all scales. However, filtering the high frequencies eliminates some of these structures, thereby reducing the system's dispersive capacity. This loss can be partially compensated for by choosing higher $\beta$ values. Furthermore, Elder's formula links the diffusion coefficient with instantaneous hydrodynamic quantities that are no longer accessible in the residual model, except in a summarized $\overline{H\|\vec{u}\|}$ form (i.e. Hü average over a tide cycle). These movements are accounted for in dispersion by giving a minimum value to the diffusion coefficient. This is provided by Lam's formula: $K_{\min }=5.10^{-4} \lambda^{1.2}$ where $\lambda$ is the patch diameter, i.e. the mesh size here. In this case, with a mesh size of $1 \mathrm{~km}$ : $\mathrm{K}_{\mathrm{min}}=7.5 \mathrm{~m}^{2} \cdot \mathrm{s}^{-1}$. Reproducing the dispersion of measured concentration fields will specify this theoretical value.

\subsubsection{Optimisations}

Time steps have been optimised by adjusting them dynamically to take into account the maximum currents calculated on the velocity field in order to have $\Delta t<\frac{\Delta x}{2\|\vec{U}\|_{\max }}$ where $\Delta x$ is the minimum size of the mesh (900m), and $\|\vec{U}\|_{\max }$ is the maximum speed calculated on the velocity field obtained for a real wind and tide at a given date. This optimisation enables the representation of strong meteorological events with reasonable average time step (1000s).

Another optimisation concerns the size of the computation area. As this kind of model works with a precalculated velocity field database, the dispersion may be computed on only part of the total model area. This area is calculated each day of simulation, surrounding of 20 kilometres the tagged plume. This method allows computing only one third of the model area on average with a single source-term and long-term simulations (more than one year). During the first months of simulation, it reduces computing time ten times more (30s for one month simulation).

Both optimisations allow simulating one year within one hour computation on a personal computer.

\section{DATABASES USED FOR SIMULATIONS}

\subsection{RADIONUCLIDE MEASUREMENT DATABASE}

\subsubsection{Surveys}

The field data for this study come from surveys carried out since 1987 in the English Channel and Irish Sea aboard vessels from the Institut Français de Recherche pour l'Exploitation de la Mer (IFREMER, Fr.), the Centre National de la Recherche Scientifique (CNRS, Fr.) and the Ministry of Agriculture, Fisheries and Food (MAFF, G.B.), and from measurements performed by the Groupe d'Etudes Atomiques (GEA, Fr.) of the French Navy and the Institut de Radioprotection et de Sûreté Nucléaire (IRSN-LRC, Fr). Most of the radionuclide concentration results presented here have already been published and discussed elsewhere 
(Bailly du Bois et al., 1993 - 1999; Guéguéniat et al., 1994 - 1997; Hermann et al., 1995). The zones covered by ocean research cruises with IRSN participation extend from the near Atlantic to Norway, with particular attention being paid to the English Channel and the southern North Sea, where discharges from the La Hague plant are dispersed.

Sampling locations used for validation are presented in Figure 5. Their distribution provides comprehensive and repetitive coverage of the area where the discharge plume from the La Hague reprocessing plant disperses in the Channel and the North Sea.

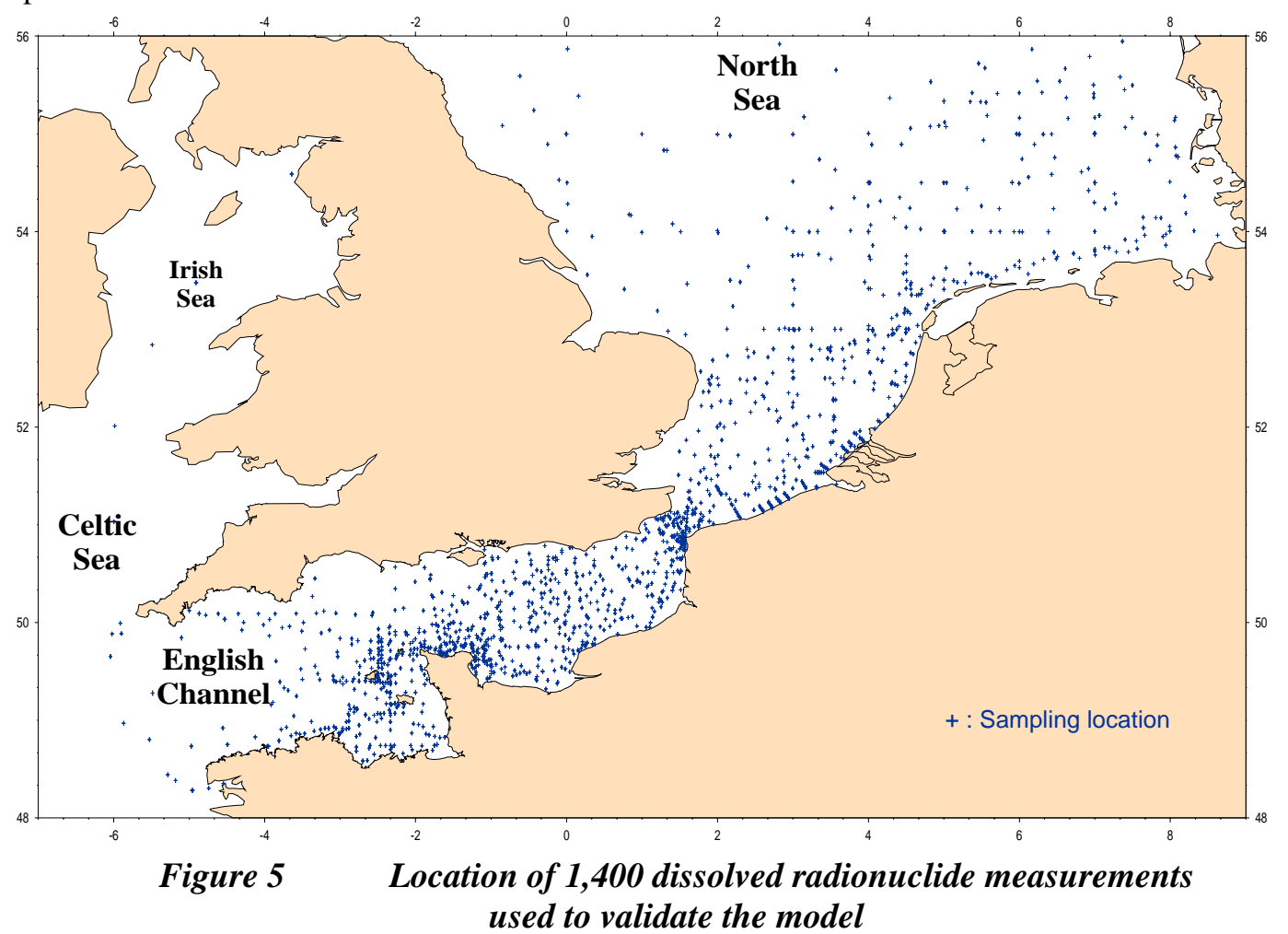

Techniques adapted for the dilution conditions observed in the marine environment and for processing samples on board were developed to measure artificial activities of the order of $0.3 \mathrm{~Bq} \cdot \mathrm{m}^{-3}$. The methods are described in Bailly du Bois et al. (1999). This value can be compared to the natural radioactivity of seawater, which is about $12,000 \mathrm{~Bq} \cdot \mathrm{m}^{-3}$. Detection of such low levels requires sample volumes ranging from 100 litres to more than a cubic metre. Errors are 50\%, 15\%, 10\% and 5\% for activities of the order of 0.7, 1.5, 5 and 15 $\mathrm{Bq} / \mathrm{m} 3$, respectively

\subsection{2. $\quad$ Processing spot measurements of concentrations}

Seawater sampling points must be positioned consistently and be referenced with respect to a fixed datum, which can be compared to that found in the residual current model. The repositioning software developed by Bailly du Bois et al (1999) was used to position all the samples taken in the Channel in the frame of reference of residual currents in barycentric coordinates.

Six sampling surveys had enough sampling stations (50 to 156 per survey) to enable the distribution of artificial radionuclides from nuclear industry releases in seawater to be mapped in the Channel and the North Sea. Spot values were interpolated over the entire area concerned during the sampling survey on a regularly meshed grid. This made it possible to make a quantitative study of the measurements acquired in seawater.

The Kriging method was used to interpolate spot values. On average, this processing gives the same results as linear interpolation by triangulation, but distributions are more homogeneous and realistic. It also provides a visual and global approach to the distribution and trends of radionuclides in the English Channel and North Sea from 1987 to 1992 (Figure 6). The measured concentration fields were drawn using the model frame and mesh size to simplify comparison with model results. Blank values were applied to areas with no measured data and theses areas were disregarded. 


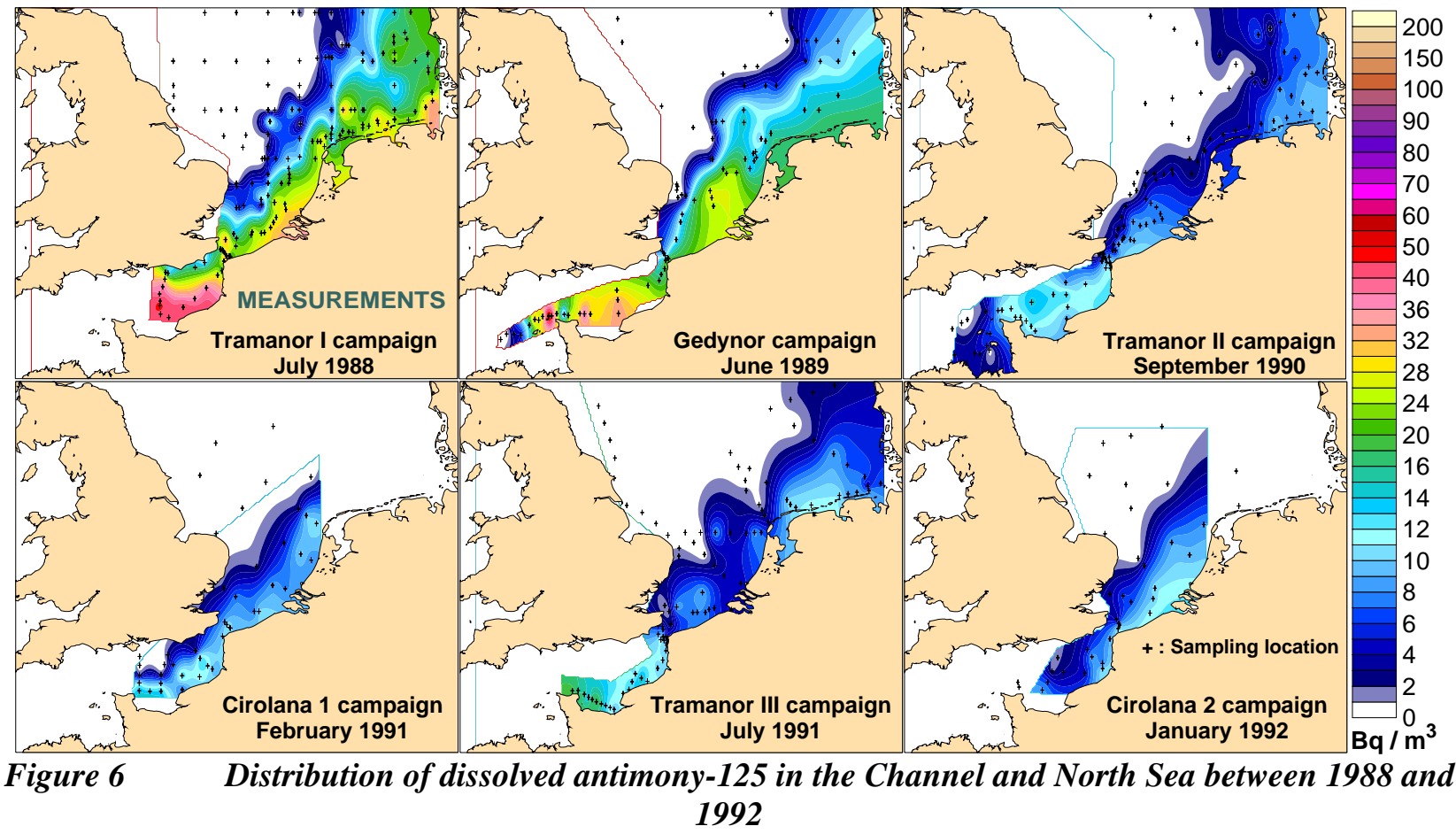

The radionuclides quantities present during the various surveys were computed by multiplying the interpolated concentration fields by bathymetry on each computational mesh. The model's bathymetry was used for this task. The quantities of radionuclides obtained could then be directly compared to results from the hydrodynamic model simulations. Such methods have been used in previous studies (Bailly du Bois et al, 1993 - 1999). The areas selected for these assessments were: the English Channel, the southern North Sea and both zones taken together.

\subsubsection{Computing the average distribution of radionuclides for a constant discharge}

Using maps representing the concentration fields at the time of each survey, normalized concentration fields can be calculated by dividing the concentration value measured or simulated in each mesh by the quantity of radionuclides released over the twelve months preceding each survey without temporal weighting. This duration correspond to the mean transit-time of releases from Cap de La Hague to Skagerrak obtained by Bailly du Bois et al (1995). The concentration distribution measured during each survey can then be quantitatively compared with other surveys. By taking the average of these normalized distributions for all surveys (II), the average distribution of the discharge plume from the La Hague plant can be visualised for a given release. In this case, a constant discharge of ${ }^{125} \mathrm{Sb}$ of $10^{6} \mathrm{~Bq} \cdot \mathrm{s}^{-1}$ has been chosen (Figure 7). The measured and simulated results can be processed in the same way, making it possible to directly compare maps obtained from these two origins.

$\operatorname{Cav}(\mathrm{i}, \mathrm{j})=\frac{\sum_{\mathrm{k}=1}^{\mathrm{nSurv}} \frac{\mathrm{C}(\mathrm{i}, \mathrm{j}, \mathrm{k})}{\mathrm{D}(\mathrm{k})}}{\mathrm{nSurv}}(\mathrm{II})$

$\operatorname{Cav}(\mathrm{i}, \mathrm{j})$ : average concentration in the mesh $\mathrm{i}, \mathrm{j}$, in Bq. $\mathrm{m}^{-3}$ corresponding to a release of $10^{6} \mathrm{~Bq} \cdot \mathrm{s}^{-1}$.

$\mathrm{C}(\mathrm{i}, \mathrm{j})$ : measured or simulated concentration in the mesh $\mathrm{i}, \mathrm{j}$, during the survey number $\mathrm{k}$, in Bq. $\mathrm{m}^{-3}$.

$\mathrm{D}(\mathrm{k})$ : discharge during the twelve months preceding the survey $\mathrm{k}$, in $10^{6} \mathrm{~Bq} \cdot \mathrm{s}^{-1}$.

nSurv : number of surveys used for quantitative budget (6)

A similar processing approach has already been used for the Channel (Bailly du Bois et al., 1999). In that comparison, the discharge and wind taken into account in the simulation were constant. The mean concentration field derived from measurement surveys was compared to the results of this theoretical simulation. As regards the comparisons performed to validate the present model, the simulations took account of real wind and releases and the standardised mean was computed using results calculated on the date of each survey. Thus, in this study, the method used to calculate mean normalized concentration maps is absolutely identical for simulated and measured concentration fields. 


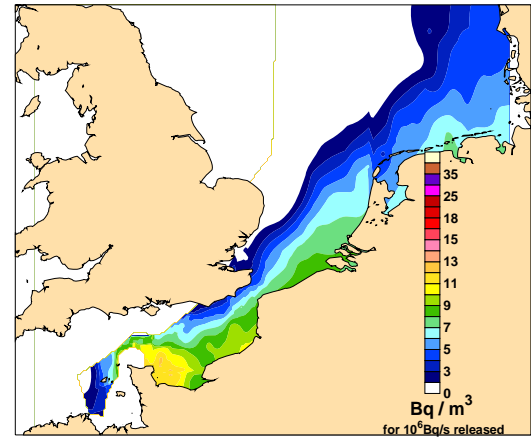

Figure $7 \quad$ Average impact of the La Hague reprocessing plant in the Channel and the North Sea for a constant release of antimony-125 of $10^{6} \mathrm{~Bq} / \mathrm{s}$, derived from in-situ measurements.

\subsection{RELEASE DATABASE}

The controlled liquid discharges from the nuclear fuel reprocessing plant at La Hague are the main source of antimony-125 in the English Channel. Releases from other nuclear facilities in the English Channel and North Sea were 100 to 1,000 times lower, and no input of releases from the Sellafield plant in the Irish Sea was identified for this radionuclide in the area studied.

The COGEMA-La Hague company has provided information on releases from the La Hague plant. This information is available for each release, back to 1982. Before this date, only monthly or annual releases are available. For each discharge since 1982, the following information is given: the start and end date and time, the volume discharged and the concentration of 22 gamma emitters, as well as tritium. The database contains 13,000 individual releases in all. Figure 8 shows the trend of annual flows of antimony-125 released since the plant started up in 1965. A sharp decline in the release of this radionuclide was observed during the validation period.

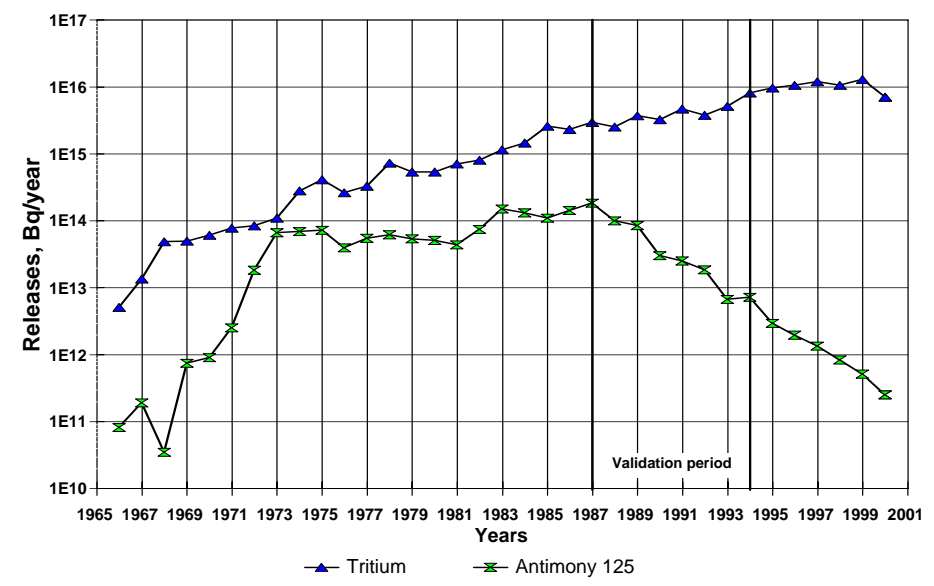

Figure 8 Annual liquid releases, in tritium and antimony-125, from the La Hague reprocessing plant in the Channel

\subsection{WIND DATABASE}

The representativeness of the wind used to force the hydrodynamic models will have a direct influence on the fine-tuning of these models. Test simulations have shown that using winds measured by weather stations located five kilometres apart (Goury semaphore at the tip of Cape La Hague and the weather station located on the La Hague plant's site) would bring about differences in the average simulated flow in the Straits of Dover by a factor of two. Even if the La Hague plant site is not an ideal location for wind measurement (70 $\mathrm{m}$ altitude, more than $2 \mathrm{~km}$ from the coast), this result highlights the importance of selecting a data set representative of the wind over the sea.

Several authors have shown that the wind's data varies considerably with the origin of the climatological data (Staneva and Stanev, 1998; Townsend et al., 2000) and the distance from the coast for the measurement location (Coelingh et al., 1996, 1998). Moreover, the computational mode for frictional stress induced by the wind on the sea surface has not been fully determined (Jones and Toba, 2001) and depend from many parameters that could not be investigated in this study (wind-wave interactions, angle between stress and wind, swell influence, unsteadiness...).

As an example, comparisons have been made between the data from the ECMWF model (European Centre for Medium-Range Weather Forecast) and observations acquired aboard oil-drilling platforms in the southern 
North Sea (Coelingh et al., 1996). They show a significant discrepancy in direction and speed, which can reach a monthly average of $1 \mathrm{~m} \cdot \mathrm{s}^{-1}$ (Figure 9). The difference in the corresponding average wind stress could reach $30 \%$.
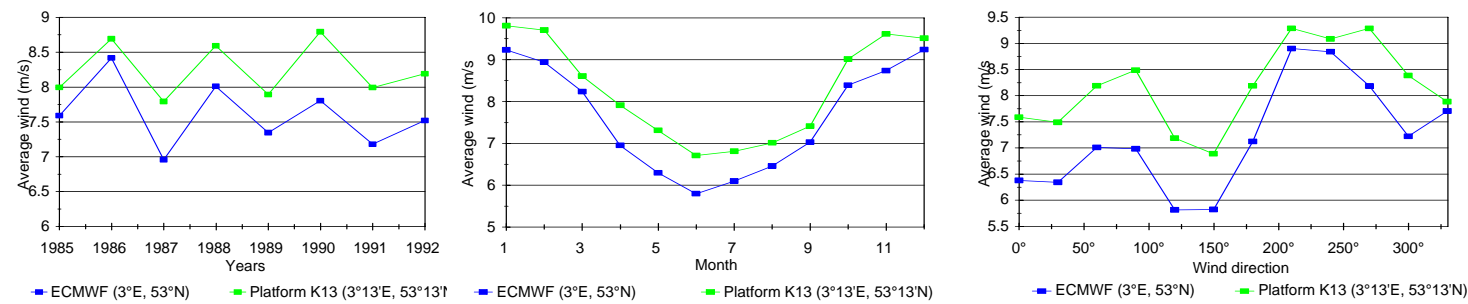

\section{Figure 9 Comparison of wind data from the ECMWF model and observations on an oil-rig in the centre of the North Sea}

By comparing data from measurements (buoys, George’s Bank) and a model (FNMOC), Manning (2001) also highlighted a systematic difference in wind direction (counter clockwise rotation of $19^{\circ}$ between the model and the measurements). The origin of wind data therefore seems to be a highly sensitive criterion in the validation of long-term dispersion models. So the calibration performed for a hydrodynamic model will be valid only for a defined and homogeneous set of data.

In order to avoid the variability associated with the specific geographical location of each observation site, the meteorological data from the European ECMWF model were collected from METEO-FRANCE. Although these are not the most accurate data presently available (satellite observations, local meteorological models, oil rigs), they provide homogeneous information over the entire model domain and over the whole period of in-situ data acquisition (1987-1994) up to the present time. Moreover, comparison of different meteorological models gives one of the best results with ECMWF data for the European area (Météo-France, 2001).

The data were computed using the ECMWF model after in-situ observations were integrated. The archives collected cover the period from 1980-2001 and indicate the wind $\left(\mathrm{W}_{\mathrm{x}}\right.$ and $\mathrm{W}_{\mathrm{y}}$ components at an elevation of $10 \mathrm{~m}$ ) for the entire western European continental shelf, with a space step of one degree longitude and latitude, and a time step of six hours.

The data's quadratic mean was computed to obtain an average daily wind, which is representative of the simulation zone. Since the winds on land are damped, only those meshes of the meteorological model located at sea were taken into account. The following zones were selected to make up six sets of wind data:

- The average of winds located over the entire model domain in the Channel and the North Sea;

- The average of winds located over the entire model domain in the North Sea;

- The average of winds located in the Channel;

- The wind data taken from the mesh at sea at a point closest to the La Hague plant outlet (longitude $2^{\circ}$ West and latitude $50^{\circ}$ North);

- The wind data taken from the mesh located at the centre of the southern North Sea (longitude $3^{\circ}$ East, latitude $54^{\circ}$ North);

- Observations from the Goury semaphore located at the tip of Cape La Hague.

\subsection{PARAMETERS TO Fine-TUNe THE MODEL}

The following parameters were used in all of the simulations:

- Duration of simulation: nine years from 01/01/1986 to 31/12/1994. This period covered most of the data acquired in-situ. Since the first available values were from 1987, the model was initialised one year ahead to perform system spin-up. Previous studies demonstrated that, on average, the antimony- 125 measured at the latitude of Denmark had been released by La Hague one year earlier (Bailly du Bois et al., 1995);

- Real discharges of antimony-125, as provided by COGEMA-La Hague, were used, taking into account the radionuclide's half-life ( 2.77 years);

- Real tide was taken into account;

- Real wind speed was taken into account (ECMWF model assimilated data or observations from the Goury semaphore).

Earlier lagrangian residual current models simulating long-term water dispersion in the Channel and the North Sea (Salomon 1988 - 1995) showed that the wind stress on the sea had to be increased in order to reproduce the water fluxes observed in-situ. For the moment, no explanation for this correction has been documented. It is not possible to determine whether it is the wind's frictional force that is poorly assessed, or 
whether the model provides poor representation of some natural phenomena. The choice of wind data used and the determination of the adjustment parameter for wind were given special attention in order to obtain a better assessment of the significance and reasons for the adjustment.

Several methods for adjusting wind data can be applied, depending on the hypotheses considered to explain the discrepancy between measured and simulated values:

- The flow of waters from the Channel towards the North Sea may not only result from direct forcing on these seas, but may also be influenced by external forcing. The simplest hypothesis is that there may be a mean sea level "slope" between the Atlantic and the North Sea due to large-scale circulation. A slope of this type can be corrected by adding a constant south-westerly component to the computed wind stress;

- A variant of the previous hypothesis is that the slope may be due to dynamic variations in sea level due to the passage of cyclonic disturbances on European epicontinental seas. A residual model using a precalculated velocity field database cannot represent such forcing. Any attempt to express this forcing for the purpose of fine-tuning the model would prove rather delicate, as the phenomenon would vary over time and be correlated to wind fluctuations without being directly linked to them. This forcing might make a significant contribution to the general circulation. It could be quantified with an instantaneous hydrodynamic model. A method to approach this phenomenon is to apply a coefficient to the wind module.

- The southern North Sea is the centre of significant baroclinic phenomena due to the Rhine plume, which is conducted to the North along Dutch coasts. The related significant density currents are located in a coastal margin of about 10-km width and 15-m height from the river mouth to the Frisian Islands. De kok (1999) assesses them, at the plume edge in the surface layer after a flood event, to $30 \mathrm{~cm} / \mathrm{s}$ to the North with a south-westerly wind of $5 \mathrm{~m} . \mathrm{s}^{-1}$; which is in this area an order of magnitude higher than the tide residual $(2 \mathrm{~cm} / \mathrm{s})$ and 5 times higher that the combined effects of the annual average wind and tide (5 $\mathrm{cm} / \mathrm{s}$ ). The concerned water seam represents about $3 \%$ of the plume of waters marked by the antimony in the southern North Sea. For the whole plume and in flood period, the contribution of these currents would represent $25 \%$ out of the total flow (tide + wind), and would not exceed $10 \%$ on average. This phenomenon is not taken into account in the instantaneous model. As these baroclinic currents are correlated to the tidal residual current associated with a southwesterly wind (direction of the annual average wind in the area), these phenomena are assimilated into the validation process of the residual model through the adjustment of the wind stress on the surface. They would result in an increase of the flow of water as well as differences between the concentrations measured and calculated along Dutch coasts between Rotterdam and Texel.

- The wind stress exerted on the sea would be poorly assessed. Several formulae to calculate stress will be tested;

It is not particularly easy to determine whether the correction should be made by adding a constant southwesterly component representing slope between Atlantic and North Sea sea level, or whether the wind module should be multiplied by a constant factor. This is because the average wind direction over the model domain is also southwesterly and the two correction methods could become mixed up in the average. It will eventually be possible to choose the hypothesis by observing how the tagged plume dispersion structures are reproduced. The adjustment sought will directly influence the speed of the structure's transport and, therefore, the phasing of events with respect to each other. With a series of peaks released at a given point, but fluctuating over time, as is the case for the La Hague plant's discharge outlet, the intensity of the correction will have a direct impact on inter-peak spacing.

The correction also affects the dilution or concentration of the plume. For steady state conditions, the flow rate in the Straits of Dover is a linear function of wind stress. So, if the release activity is equal, increasing the component ( $\left.\tau \mathrm{x}_{\text {added }}, \tau \mathrm{y}_{\text {added }}\right)$ in the southwesterly direction, increases the flow rate in the Straits of Dover and decreases the average concentration of substances transported in the Channel "river".

If the best adjustment is obtained by increasing the wind stress, that would suggest that the frictional force is poorly assessed, and/or that a phenomenon correlated to the wind's action is poorly assessed.

To sum up, wind-induced stress was parameterised by taking the following elements into account:

- Origin of the raw wind data:

-Measurements from the semaphore at Cape La Hague;

-Assimilated data from the ECMWF numerical model supplied by METEO-FRANCE.

- 5 computation zones of mean wind for wind data from the meteorological model were tested (see section 3.3);

- $\mathrm{x}$ and $\mathrm{y}$ components of added constant wind stress;

- Multiplying (or power) factor applied to the wind.

In (I), with multiplying factor $\mathrm{f}$ : $\mathrm{Cdf}=\mathrm{f}^{2} \mathrm{xCd}$, with $\mathrm{C}_{\mathrm{df}}$ the drag coefficient after applying multiplying 
factor.

With a power factor $\mathrm{p}$ : $\mathrm{Cd}=0.0015 \mathrm{x}\|\overrightarrow{\mathrm{W}}\|^{\mathrm{p}}\left(\|\overrightarrow{\mathrm{W}}\|\right.$ the wind vector module $\left(\mathrm{W}_{\mathrm{x}}, \mathrm{W}_{\mathrm{y}}\right)$ at $\left.10 \mathrm{~m}\right)$;

- Formula to compute wind stress. Eight different formulae were tested. The one recommended by Amorocho and de Vries (1980) has been applied in sections $4.2-4.5, C_{d}$ is in the form:

$$
\mathrm{Cd}=\frac{0,0015}{1+\mathbf{e}^{\frac{\|\overrightarrow{\mathrm{w}}\|-12,5}{-1,56}}}+0,00104
$$

- Minimum diffusion coefficient representing the dispersion related to instantaneous currents will have to be adjusted.

\subsection{REPRESENTATIVE INDICES FOR MODEL VALIDATION}

Validation of the model was based on approximately one thousand simulations each lasting nine years (1986 - 1994). In order to compare all the results, a set of test parameters was defined to provide a summarised view of how measured and simulated values correspond.

The following values were computed for each of the simulations carried out:

- Each day of simulation:

- Mean water fluxes in the Straits of Dover (MF);

- Mean wind stress applied (module and direction) (MW).

- For all of the 1,400 spot measurements acquired in-situ, calculations were based on series of measured and computed concentrations at the same place and on the same dates:

- Correlation coefficient (CC);

- The mean absolute value of standard deviations (MV): $\sum_{\mathrm{n}=1}^{\mathrm{n} \text { Meas }}$ Abs $\left(\frac{\text { SimConc }- \text { MeasConc }}{\text { MeasConc }}\right) / \mathrm{nMeas}$;

SimConc: simulated concentration

MeasConc: measured concentration

nMeas: $\quad$ number of measures

Abs: function giving the absolute value

- $95^{\text {th }}$ percentile of the ratio (R) between measured and computed concentrations (P95):

$\mathrm{R}=$ Maximum $\left\lfloor\left(\frac{\text { SimConc }}{\text { MeasConc }}\right),\left(\frac{\text { MeasConc }}{\text { SimConc }}\right)\right]$ (III).

- For the 6 main sampling surveys, which concern 555 individual measurements, the following values were computed:

- Radionuclide concentration field on the date of each survey over the entire simulation domain;

- Quantitative variation in \% between the total amounts measured and the total amounts computed for the Channel, the North Sea and both the Channel and the North Sea (QV);

100x $\left(\sum_{\mathrm{k}=1}^{\mathrm{k} \max }\left(\sum_{\mathrm{i}=1}^{\mathrm{i} \max } \sum_{\mathrm{j}=1}^{\mathrm{jmax}} \operatorname{SimConc(i,j,k)}-\sum_{\mathrm{i}=1}^{\mathrm{i} \max } \sum_{\mathrm{j}=1}^{\mathrm{j} \max } \operatorname{MeasConc(i,j,k)}\right) / \sum_{\mathrm{i}=1}^{\mathrm{i} \max } \sum_{\mathrm{j}=1}^{\mathrm{jmax}} \operatorname{MeasConc(i,j,k)}\right) / \mathrm{k} \max$

$\mathrm{i}, \mathrm{j}$ : lines and column indices in the concentration field (from model or measurements)

imax, jmax: maximum values for lines and column indices in the concentration field

$\mathrm{k}$, kmax: $\quad$ index and maximum index (6) of surveys.

This index is relevant as long as systematic errors are removed from radionuclide concentration measurements in seawater or in the released water. ${ }^{125} \mathrm{Sb}$ and ${ }^{3} \mathrm{H}$ are measured on different samples with different techniques (gamma counting after co-precipitation and liquid scintillation after electrolytic enrichment respectively). In addition, radionuclide quantities are balanced for ${ }^{125} \mathrm{Sb}$ and ${ }^{3} \mathrm{H}$ together (Bailly du Bois et al., 1999). Thus, over- or under-estimation of radionuclides quantities can be excluded. A significant adsorption of ${ }^{125} \mathrm{Sb}$ onto sediment is excluded because it would have given ${ }^{125} \mathrm{Sb}$ distribution in the North Sea and in the English Channel different from measurements (Bailly du Bois et al, 1995, 1999). Finally, the impact of bathymetric uncertainties is removed by using the same bathymetry dataset for measured and simulated inventories.

In conclusion the budget of total ${ }^{125} \mathrm{Sb}$ inventory appears as a robust index, and the adjustment of model calculation parameters is based first on this budget. If the error on individual measurements is on average $15 \%$, the error concerning the total inventory of radionuclides is $0.6 \%$. A difference of less than $1 \%$ in the variation between total measured and simulated amounts of radionuclides will therefore be sought for model calibration.

- The mean concentration field of the 6 main sampling surveys was computed for each simulation using the method described in section 3.1.2.1, so that it could be compared with the data from Figure 7. 
Using the mean normalized concentrations map for each simulation and the map of mean normalized concentrations measured, the following values were calculated:

- Mean of square root differences between all meshes; (MS)

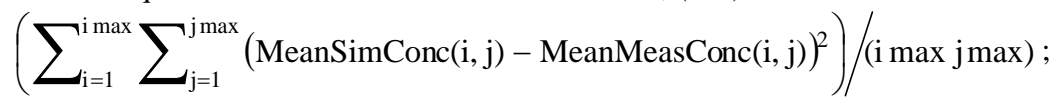

MeanSimConc:

normalized mean simulated concentration

MeanMeasConc:

normalized mean measured concentration

- Difference in \% between the mean computed and simulated concentrations over the entire area (DM).

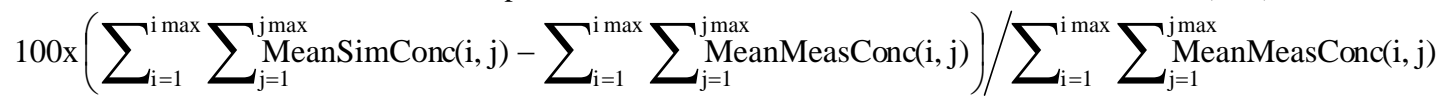

Simulation parameters are adjusted with a view to simultaneously optimising all of the indices by bringing them closer to the following theoretical values:

- The deviation between the measured quantities and the computed quantities for the channel, the North Sea and both the Channel and North Sea = 0;

- Mean or sum of the deviations or the deviance $->0$;

- Correlation coefficients -> 1;

- $\quad$ The 95th percentile of the ratio between measured concentrations-> 1;

- Mean of the square root differences of all the normalized mean distribution meshes ->0;

- Mean water fluxes in the Straits of Dover close to already published values: $114,000 \mathrm{~m}^{3} . \mathrm{s}^{-1}$ (Salomon et al., 1993: numerical model) $-130,000 \mathrm{~m}^{3} . \mathrm{s}^{-1}$ (Bailly du Bois et al., 1995: quantitative radionuclide budget) - 94,000 $\mathrm{m}^{3} . \mathrm{s}^{-1}$ (Prandle et al, 1996: HF radar and ADCP measurements).

Taking these calibration indices into account may seem unnecessary, since some of them are interrelated: standard deviation and correlation coefficient; mean deviation and differences in quantities calculated and measured. However, all these indications do not always converge simultaneously, so it is possible to obtain a high correlation coefficient with differences in the quantities of simulated substances of over 50\%. Moreover, the different indices do not concern the same data sets (for instance, individual measurement values and average survey values). The balance of radionuclide quantities, which is based on 555 individual measurements, is used to adjust calibration parameters. Indices that represent differences between individual measured and simulated concentrations (CC, MV and P95), are based on a total of 1,400 measurements. These indices represent the main validation parameters.

It is essential to perform a visual check of the correspondence between the computed and measured distribution maps on the date of each survey and the comparison between the standardised calculated and measured mean distribution maps. These visual checks, which cannot be reduced to numerical values, provide an assessment of the spatial distribution of dispersion plumes and the correspondence between measured and simulated distributions.

\section{VALIDATION RESULTS}

Since several parameters may be adjusted, numerous tests were necessary to assess the combined influence of various parameters (choice of wind, multiplying factor, added stress, computational formula, etc.). Adjusting for a single parameter requires an average of five simulations in order to minimise the discrepancy between the measured and calculated quantities of radionuclides over the entire Channel and North Sea. The tolerance chosen for this discrepancy was about one percent. The most significant results selected among the thousand simulations performed are presented here.

\subsection{COMPARISON OF MODEL/MEASUREMENTS WITHOUT CALIBRATION (REFERENCE RUN)}

The computational parameters applied at the outset were those which seemed the most logical, a-priori, to simulate the dispersion of a substance in the Channel and the North Sea:

- The wind data was taken from the ECMWF model, the area considered to calculate the mean wind covered all of the wind data located in the release plume dispersion zone in the Channel and in the southern North Sea;

- $\quad$ The wind multiplying factor was 1 ;

- $\quad$ There was no added wind component;

- $\quad$ The computational formula for stress applied is that recommended in section 2.2 (I) where Cd $=0.0015$. 
The values obtained for the various comparison indices are given in Table 2. The distribution of concentrations obtained on the date of the six main measurement surveys is shown in Figure 10. It can be compared with maps obtained from measurements (Figure 6). The mean distribution of the calculated concentrations is given in Figure 11, which reproduce also the map obtained from measurements (Figure 7).

\begin{tabular}{|c|c|c|c|c|c|c|c|c|c|c|}
\hline \multirow{2}{*}{\multicolumn{3}{|c|}{$\begin{array}{c}\text { QV } \\
\text { Quantitative variation } \\
\text { for the six main } \\
\text { campaigns }\end{array}$}} & \multicolumn{3}{|c|}{ Individual measurements } & \multicolumn{2}{|c|}{$\begin{array}{c}\text { Mean } \\
\text { distribution }\end{array}$} & \multirow{3}{*}{$\begin{array}{c}\text { MF } \\
\text { Mean flux } \\
\text { through } \\
\text { the Dover } \\
\text { Strait } \\
\left(\mathrm{m}^{3} . \mathrm{s}^{-1}\right)\end{array}$} & \multirow{2}{*}{\multicolumn{2}{|c|}{\begin{tabular}{|} 
MW \\
Mean wind \\
stress \\
Value
\end{tabular}}} \\
\hline & & & CC & MV & & $\mathrm{DM}$ & MS & & & \\
\hline $\begin{array}{c}\text { Whole } \\
\text { area }\end{array}$ & $\begin{array}{c}\text { North } \\
\text { Sea }\end{array}$ & \begin{tabular}{|l|} 
English \\
Channel
\end{tabular} & $\begin{array}{l}\text { Correl. } \\
\text { Coef. }\end{array}$ & $\begin{array}{c}\text { Mean } \\
\text { Variation }\end{array}$ & $\begin{array}{l}95 \% \mathrm{r} \\
\text { Meas/ }\end{array}$ & $\begin{array}{l}\text { mean } \\
\text { conc. }\end{array}$ & $\begin{array}{l}\text { square } \\
\text { diff. }\end{array}$ & & $\left(\mathrm{N} \cdot \mathrm{m}^{-2}\right)$ & Dir. \\
\hline $83 \%$ & $100 \%$ & $\%$ & 0.858 & $106 \%$ & & $76 \%$ & 25 & & 0.052 & $248^{\circ}$ \\
\hline
\end{tabular}

\section{Table 2 Indices of model/measurement comparison without model calibration}

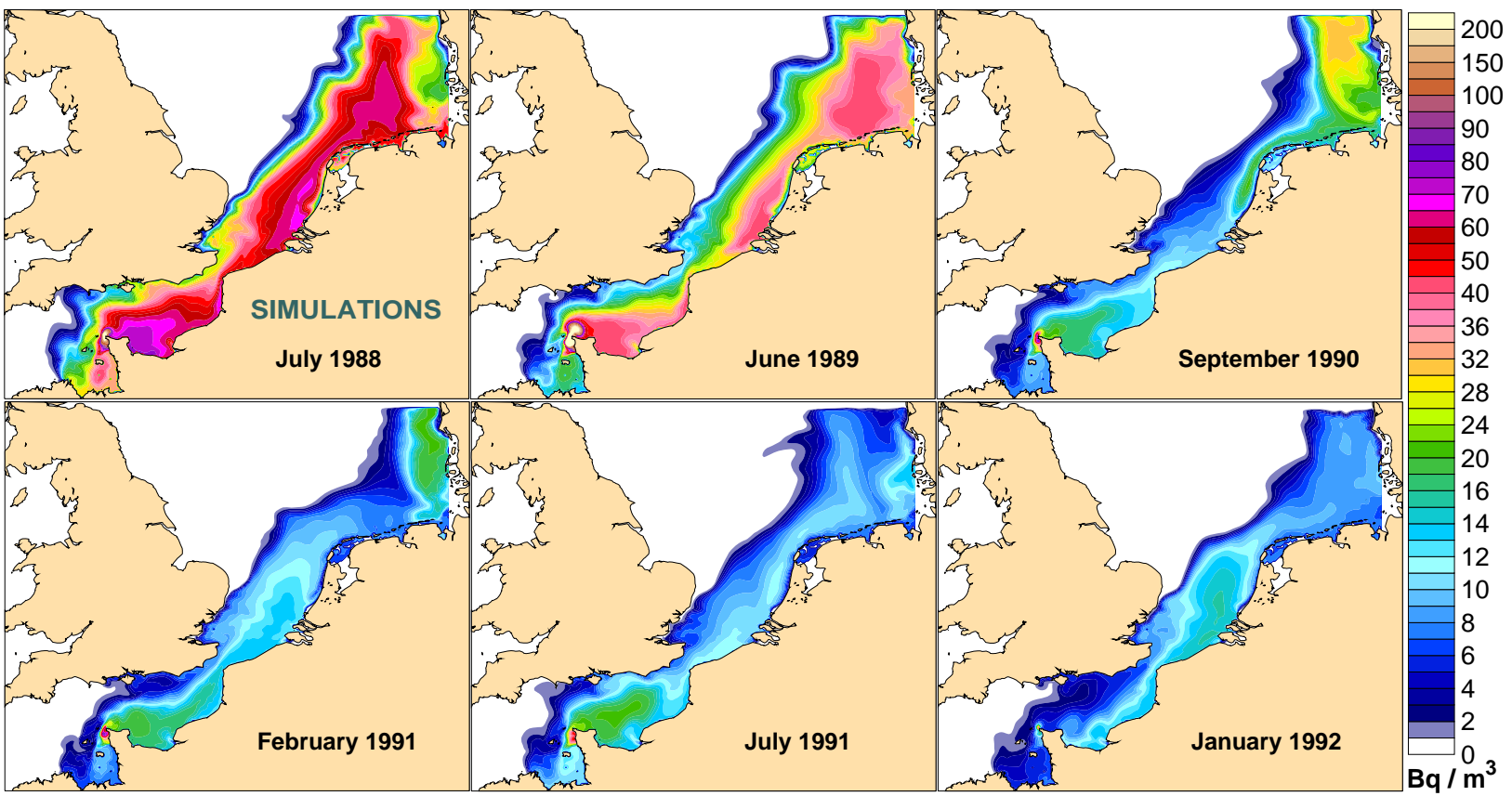

Figure 10 Simulation of the distribution of dissolved antimony-125 in the Channel and North Sea between 1988 and 1992, without model calibration.

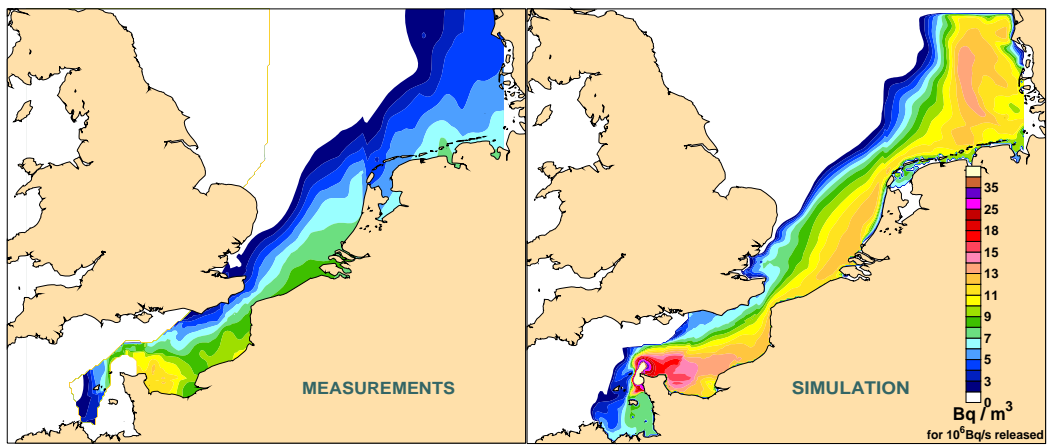

Figure 11 Simulation of average impact of the La Hague reprocessing plant in the Channel and the North Sea for a constant release of antimony-125 of $10^{6} \mathrm{~Bq} / \mathrm{s}$, without model calibration.

(Computation using simulated concentrations on the dates of 6 measurement surveys used quantitatively)

Although the spatial distribution of the simulated plume is close to that calculated from the measurements, the concentrations and the quantitative assessments obtained are very different. On average, the calculated quantities are almost twice as high as those measured over the entire domain. A comparison of the measured distributions (Figure 6) and those calculated (Figure 10) also shows a very different plume distribution for the six measurement surveys.

\subsection{WIND COMPUTATION ZONE}

The six sets of wind data selected (section 3.3) were calibrated in order to obtain a mean deviation near zero between the measured and calculated quantities. The Amorocho (1980) drag law was used and deviation minimised with a wind-multiplying factor (f, see section 3.4). The correlation coefficient (Table 3) between the measured and calculated concentrations increased when applying the following elements, in this order: 
observations from the Goury semaphore at Cape La Hague, wind from the ECMWF meteorological model at coordinates longitude $3^{\circ}$ East, latitude $54^{\circ}$ North, the mean wind of the North Sea; the mean wind of the Channel and the North Sea; the mean wind of the Channel and the wind at coordinates longitude $2^{\circ}$ West, latitude $50^{\circ}$ North.

The last two wind computation zones give similar results. The correlation coefficient for mean wind from the Channel (0.882) is slightly higher than that obtained with wind in the centre of the Channel (0.869). The quantity assessment in the Channel and the North Sea, however, is more homogeneous for the wind in the centre of the Channel ( $+1 \% /-1 \%$ compared to $+2 \% /-3 \%)$ and the difference from the values measured on the mean distributions is lower (3\% compared to 5\%), as is the wind-multiplying factor (1.47 compared to 1.5). For these reasons, the wind calculated in the centre of the Channel was selected as a reference for the rest of the validation.

These results seem to indicate that the wind-induced dispersion near the outlet point is decisive for the later distribution of the plume: the initial plume signal modulations remain and are hardly altered by long-term hydrodynamic fluctuations. The special situation at the discharge point of the La Hague plant may contribute to amplifying the importance of local wind for long-term dispersion. In the case of southerly and westerly forcing, residual stream (Figure 4) shows that the entire release will be carried away in the Channel flux towards the North Sea. In the case of northerly and easterly forcing, a significant portion of the release will be excluded from this flux by being directed towards the Normand-Breton gulf, which has a considerable retention effect (cf. gyres in Figure 4). It will only be progressively re-introduced into the general flux.

The poorest results obtained with data from the Goury semaphore confirmed that land-based meteorological observations do not well represent offshore wind. The influence of land can be perceptible at over $50 \mathrm{~km}$ from the shore (Coelingh et al., 1996). However, the values measured at Goury exhibited greater variability in direction and amplitude than the ECMWF model. On average, the sum of wind-induced frictional forces on the sea surface measured at Goury was $15 \%$ higher. Since these observations were made in the coastal zone, it is likely that the model significantly underestimates the real wind speed and energy in the centre of the English Channel.

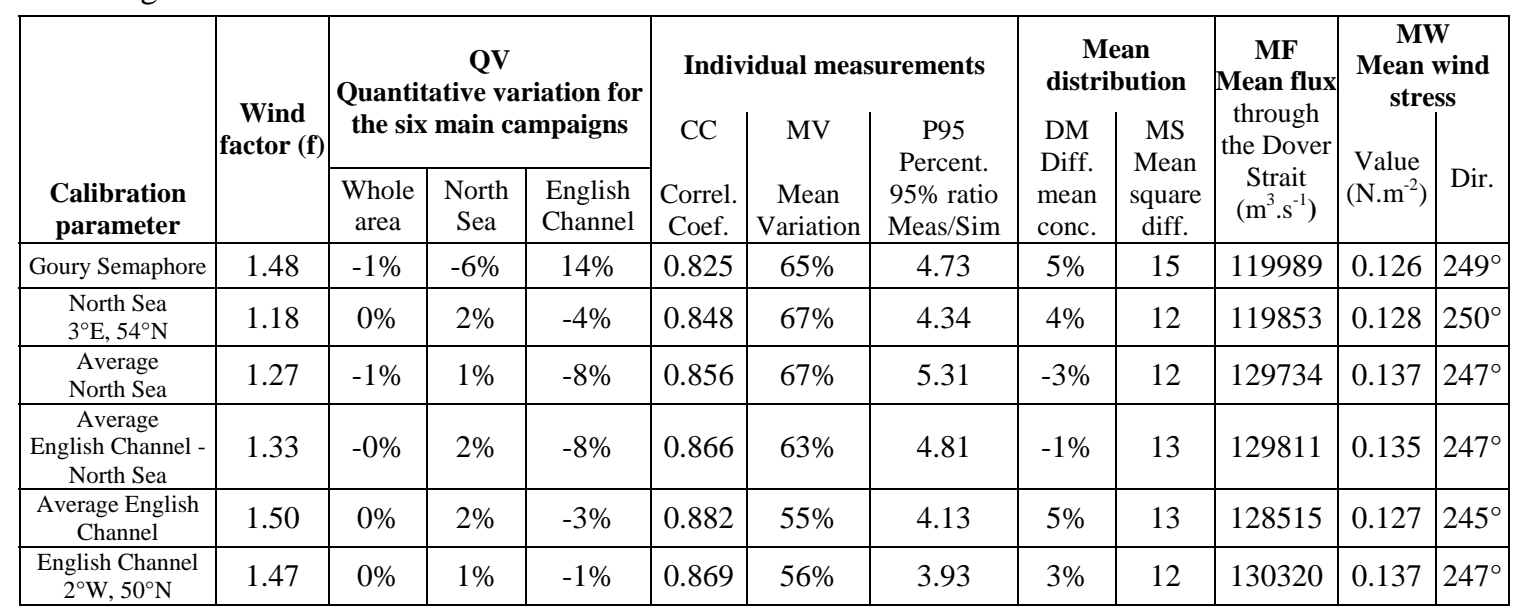

Table 3 Indices of model/measurement comparison as a function of wind computation zones

\subsection{AdDing A CONSTANT STRESS}

Assuming that the deviation between the measured and calculated quantities of radionuclides is due to poor knowledge of a mean flux between the Atlantic and the North Sea, it is possible to take this slope at sea level into account by applying a constant stress in a south-south-westerly direction. In order to balance the quantities of simulated and measured radionuclides, stress in the direction of $194^{\circ}$ with a modulus of $0.084 \mathrm{~N} . \mathrm{m}^{-2}$ must be added. This strong forcing with respect to the stress due to the wind alone (direction: $248^{\circ}$, modulus: $0.052 \mathrm{~N} . \mathrm{m}^{-2}$ ) brings about a "smoothing” of the dispersion plume (Figure 12), which does not reproduce the observed variability of distributions (Figure 6). Moreover, although a smoothed distribution has a better chance of entailing good correlation coefficients, the correlation coefficient obtained for all the points (Table 4) is lower than that obtained with a wind multiplying factor (0.835 instead of 0.869 ). This shows that the wind-induced plume fluctuations bring about a spatial distribution of the plume, which is more in keeping with the observations. The mean flux through the Dover Strait $\left(171,254 \mathrm{~m}^{3} . \mathrm{s}^{-1}\right)$ is high compared to previous results from model and measurements (Prandle et al, 1996; Salomon et al, 1993; Bailly du Bois et al, 1993; detail in 4.6).

Theses results suggest that, if a sea slope between the Atlantic and the North Sea exists, it has not a strong influence on radionuclides fluxes through the English Channel and the North Sea. 


\begin{tabular}{|c|c|c|c|c|c|c|c|c|c|c|c|c|}
\hline \multirow[b]{2}{*}{$\begin{array}{l}\text { Calibration } \\
\text { parameter }\end{array}$} & \multirow{2}{*}{$\begin{array}{c}\text { Wind } \\
\text { factor (f) }\end{array}$} & \multicolumn{3}{|c|}{\begin{tabular}{|c|} 
QV \\
Quantitative variation for \\
the six main campaigns
\end{tabular}} & \multicolumn{3}{|c|}{ Individual measurements } & \multicolumn{2}{|c|}{$\begin{array}{c}\text { Mean } \\
\text { distribution }\end{array}$} & \multirow{2}{*}{$\begin{array}{c}\text { Mean flux } \\
\text { through } \\
\text { the Dover } \\
\text { Strait } \\
\left(\mathrm{m}^{3} \cdot \mathrm{s}^{-1}\right)\end{array}$} & \multicolumn{2}{|c|}{$\begin{array}{c}\text { MW } \\
\text { Mean wind } \\
\text { stress } \\
\text { (wind added } \\
\text { included) }\end{array}$} \\
\hline & & $\begin{array}{l}\text { Whole } \\
\text { area }\end{array}$ & $\begin{array}{l}\text { North } \\
\text { Sea }\end{array}$ & $\begin{array}{l}\text { English } \\
\text { Channel }\end{array}$ & $\begin{array}{l}\text { Correl. } \\
\text { Coef. }\end{array}$ & $\begin{array}{c}\text { Mean } \\
\text { Variation }\end{array}$ & $\begin{array}{l}\text { Percent. } \\
\text { 95\% ratio } \\
\text { Meas/Sim }\end{array}$ & $\begin{array}{l}\text { Diff. } \\
\text { mean } \\
\text { conc. }\end{array}$ & $\begin{array}{l}\text { Mean } \\
\text { square } \\
\text { diff. }\end{array}$ & & $\begin{array}{c}\text { Value } \\
\left(\mathrm{N} . \mathrm{m}^{-2}\right)\end{array}$ & Dir. \\
\hline
\end{tabular}

\section{Table $4 \quad$ Indices of the model/measurement comparison after adding a constant stress}

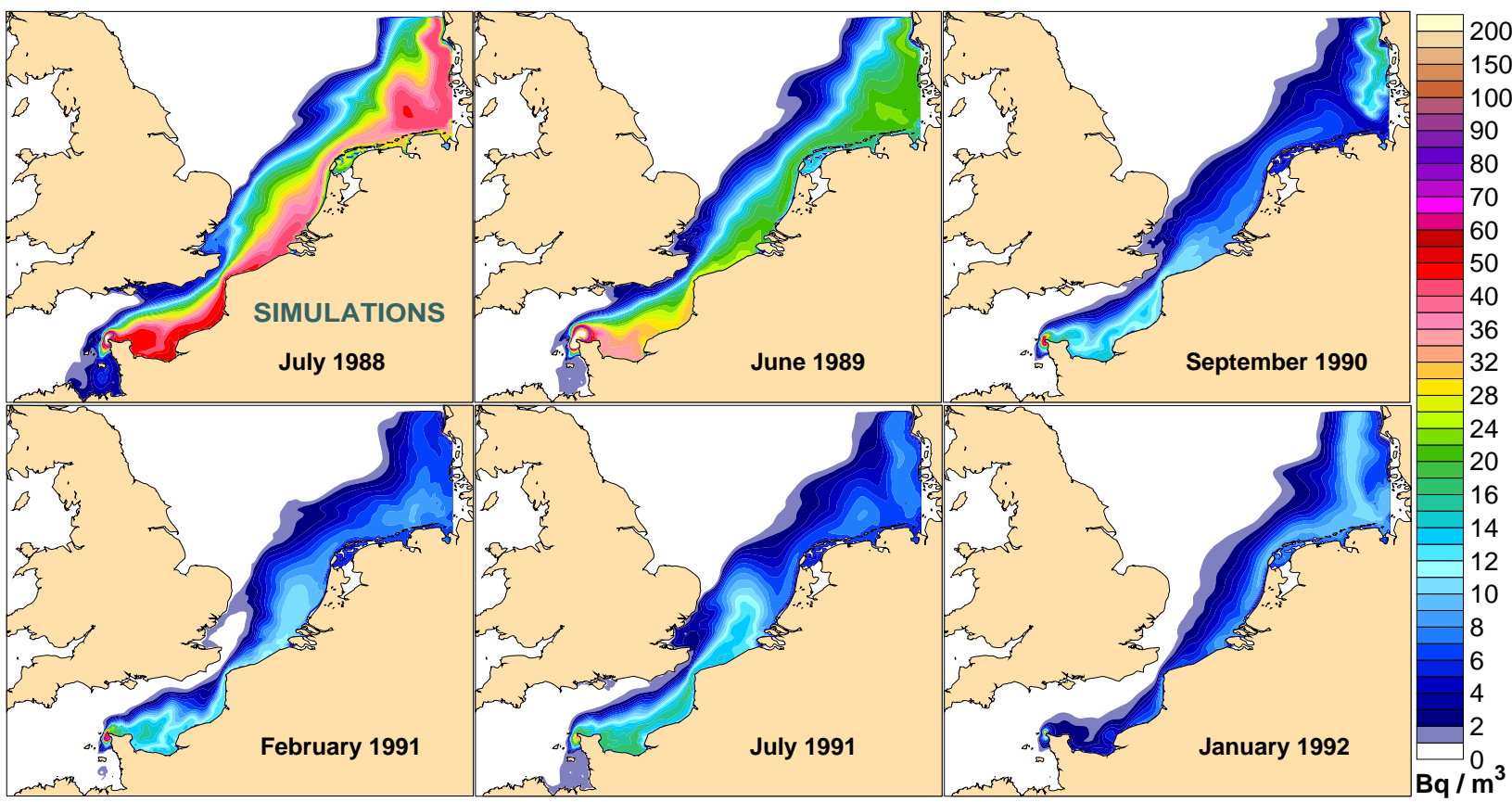

Figure 12

Simulation of the distribution of dissolved antimony 125 in the Channel and the North Sea between 1988 and 1992, after adding a constant stress $\left(\right.$ dir $\left.=194^{\circ}, \tau=0.084\right)$

\subsection{MULTIPLYING THE WIND BY A CONSTANT FACTOR}

Since the mean wind direction is close to that inducing the largest flux from the Channel towards the North Sea, taking a wind-multiplying factor into account can have an average impact comparable to that obtained by adding a wind from the southwestern sector. However, the wind's variability over time is still represented, including the periods when the wind was blowing in the opposite direction to the mean flow. This results in a much more heterogeneous distribution of the dispersion plume. By applying this method, the best agreement between calculated and simulated values was obtained with a multiplying factor (f) of 1.47 applied to wind data from the ECMWF model in the longitude $2^{\circ}$ West and latitude $50^{\circ}$ North coordinates mesh. The results are presented in the last line of Table 3.

When distribution maps are compared to the maps obtained from measurements, the average distributions are quite close. The spatial distribution of the concentration gradients for each campaign is well reproduced overall, although calculated concentrations are systematically higher in the German Bight.

\subsection{WIND STRESS COMPUTATION FORMULA}

The basic formula used to calculate the wind stress is given in section 2.2 above (I). Other drag coefficient formulations have been proposed (Heaps, 1965; Garratt, 1977; Amorocho and de Vries, 1980; Wu, 1980; Proctor, 1990). Figure 13 shows how wind stress evolves as a function of wind speed for the various formulae tested. The formula inducing the highest stress for a given wind speed quite logically gave the best results. This was particularly true of the formula recommended by Amorocho and de Vries (1980, section 3.4)

In practice, the correction factor applied to calculate the wind stress is such that the formulae used does not significantly change the results obtained. Starting from the generic formula (I), it is possible to either increase the drag coefficient $C_{d}$, or to make $C_{d}$ vary as a function of $\|\vec{W}\|$ with a power factor $\mathrm{P}$ such that 
$\mathrm{C}_{\mathrm{d}}=0.0015 \mathrm{x}\|\vec{W}\|^{\mathrm{P}}$. The curves showing the trend of stress as a function of wind speed are appreciably different with these two methods (Figure 13). Nevertheless, both approaches give close results for the model/measurement comparison (Table 5). The mean distribution of antimony-125 obtained using the two methods is shown in Figure 14. Thus, the way the stress is computed seems less important than the mean forcing that must be applied. Inaccuracy related to the origin of the wind data induces much greater discrepancies. This is illustrated in Table 3 showing results obtained from Goury semaphore wind observations, and results obtained from ECMWF data at the same location $\left(2^{\circ} \mathrm{W}, 50^{\circ} \mathrm{N}\right)$.

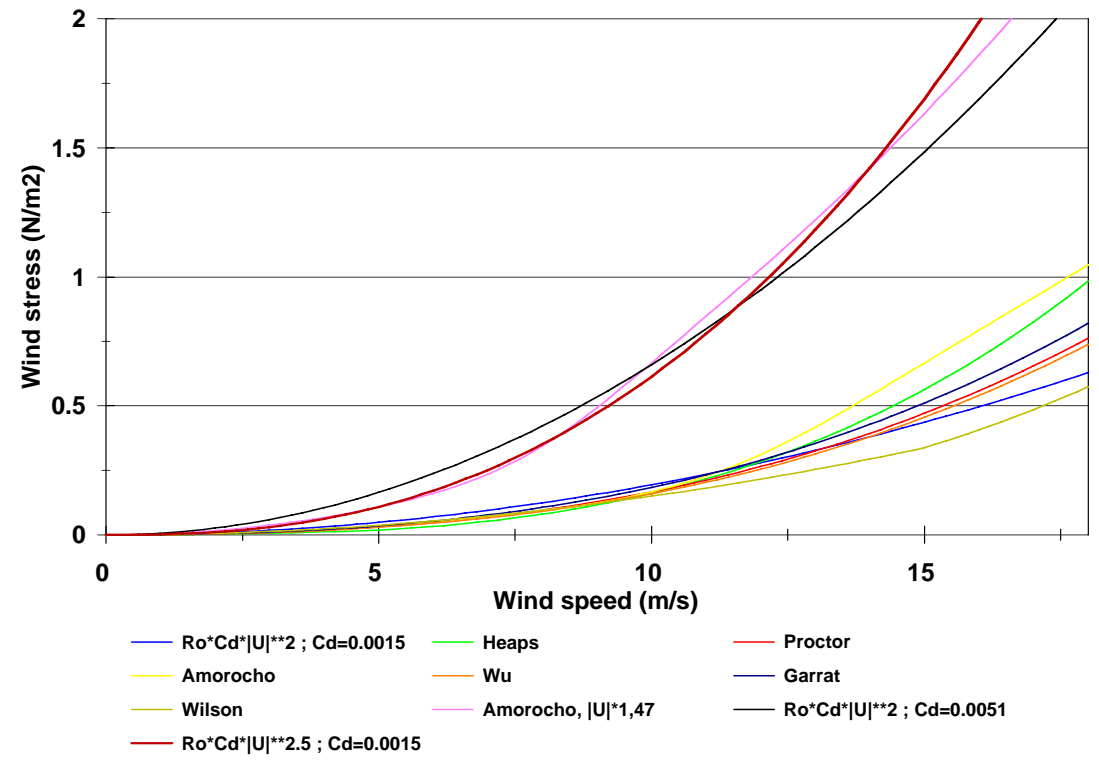

Figure $13 \quad$ Wind stress as a function of wind speed for the different formulae used

\begin{tabular}{|c|c|c|c|c|c|c|c|c|c|c|c|c|}
\hline \multirow{3}{*}{$\begin{array}{c}\text { Calibration } \\
\text { parameter (wind } \\
\text { stress formula) }\end{array}$} & \multirow{3}{*}{ Wind factor } & \multirow{2}{*}{\multicolumn{3}{|c|}{\begin{tabular}{|c|} 
QV \\
$\begin{array}{c}\text { Quantitative variation } \\
\text { for the six main } \\
\text { surveys }\end{array}$ \\
\end{tabular}}} & \multicolumn{3}{|c|}{ Individual measurements } & \multicolumn{2}{|c|}{$\begin{array}{c}\text { Mean } \\
\text { distribution }\end{array}$} & \multirow{3}{*}{\begin{tabular}{|c|} 
MF \\
Mean flux \\
through \\
the Dover \\
Strait \\
$\left(\mathrm{m}^{3} . \mathrm{s}^{-1}\right)$ \\
\end{tabular}} & \multicolumn{2}{|c|}{$\begin{array}{l}\text { Mean wind } \\
\text { stress }\end{array}$} \\
\hline & & & & & \multirow{2}{*}{$\begin{array}{l}\text { CC } \\
\text { Correl. } \\
\text { Coef. }\end{array}$} & \multirow{2}{*}{\begin{tabular}{c|} 
MV \\
Mean \\
variation
\end{tabular}} & \multirow{2}{*}{\begin{tabular}{|c|} 
P95 \\
Percent. \\
95\% ratio \\
Meas/Sim
\end{tabular}} & \multirow{2}{*}{$\begin{array}{l}\text { DM } \\
\text { Diff. } \\
\text { mean } \\
\text { conc. }\end{array}$} & \multirow{2}{*}{$\begin{array}{l}\text { MS } \\
\text { Mean } \\
\text { square } \\
\text { diff. }\end{array}$} & & \multirow{2}{*}{$\begin{array}{c}\text { Value } \\
\left(\mathrm{N} \cdot \mathrm{m}^{-2}\right)\end{array}$} & \multirow{2}{*}{ Dir. } \\
\hline & & \begin{tabular}{|c|}
$\begin{array}{c}\text { Whole } \\
\text { area }\end{array}$ \\
\end{tabular} & $\begin{array}{l}\text { North } \\
\text { Sea }\end{array}$ & \begin{tabular}{|c|} 
English \\
Channel
\end{tabular} & & & & & & & & \\
\hline & & & & & \begin{tabular}{|l}
0.869 \\
\end{tabular} & & & $3 \%$ & 4 & & & 24 \\
\hline & & & 170 & 110 & 0.872 & 560 & & 3 & 12 & 130448 & 6 & 24 \\
\hline $\mathrm{C}_{\mathrm{d}}=$ & ju & $-1 \%$ & $-1 \%$ & $1 \%$ & 0.86 & 61 & & $4 \%$ & 12 & 320 & 0.137 & 24 \\
\hline
\end{tabular}

Table $5 \quad$ Indices of the model/measurement comparison modifying the wind stress computation formula
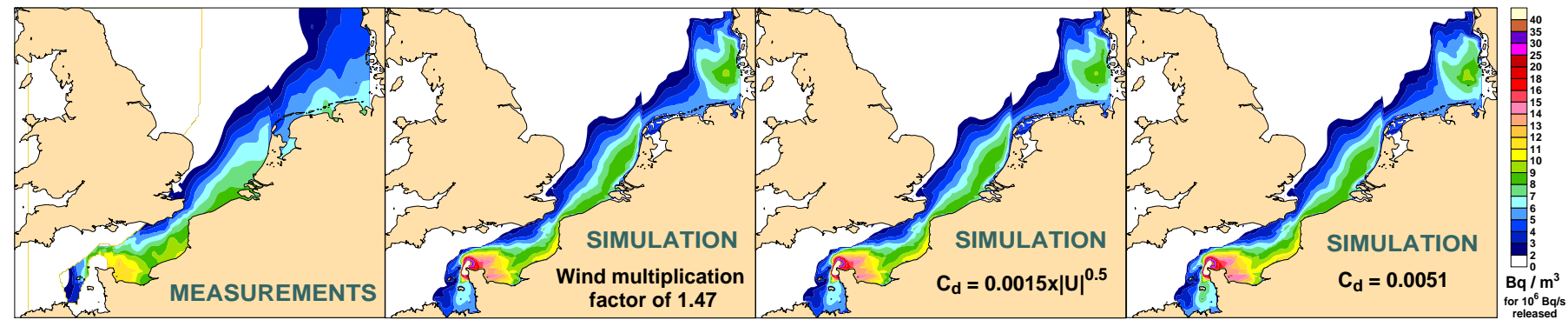

Figure 14

Simulation of the mean distribution of dissolved antimony-125 in the Channel and North Sea between 1988 and 1992 by modifying the wind stress bulk formula

The overall correlation coefficient obtained by varying the power (p) term is slightly higher than that obtained using Amorocho's formula or varying the drag coefficient (Table 5: 0.872 compared to 0.869 and 0.867 respectively). Other simulations performed using similar parameters confirmed this difference and showed better indices on average with this formulation (correlation coefficients, balance of quantities in the Channel and the North Sea, mean deviation, mean flux in the Straits of Dover). Therefore, this was the computation method selected where $C_{d}=0.0015 \mid \vec{w} \|^{\mathrm{p}}$; $p$ is variable, adjusted to minimize the difference between measured and calculated quantities. 


\subsection{RESULTS FROM MODEL/MEASUREMENT COMPARISON WITH RECOMMENDED PARAMETERS}

From all the tests performed, it emerges that the main calibration parameter for the model is the choice of wind and computational mode of the stress induced by this wind. The recommended values are:

- Use the wind data from the ECMWF model, and find the values located at sea in the zone closest to the release point $\left(50^{\circ} \mathrm{N}, 2^{\circ} \mathrm{W}\right.$ in this study);

- Apply a minimum diffusion coefficient of $50 \mathrm{~m}^{2} \cdot \mathrm{s}^{-1}$. The initial value was 7.5, the increase of this value results in a slight spreading of the dispersion plume towards the English Channel centre where residual speeds are greater. The consequence is that the forcing applied to the wind to balance the flows is slightly weaker ( $\mathrm{p}=0.48$ instead of 0.50$)$

- Compute wind stress using the formula presented in section 2.2 (I), with the drag coefficient $C_{d}=0.0015$ $\mathrm{x}\|\mathrm{W}\|^{0.48}$;

- The origin of wind data is decisive (cf. 3.3). Using other wind data sets would give noticeably different results (see Table 3). Table 7 gives an example of model results with recommended parameters and wind data measured at the Goury semaphore (situated close to the location of the recommended wind data). Despite the fact that radionuclide quantities are balanced for the whole area, there is a clear difference between the North Sea and English Channel quantities when considered individually, and correlation indices are lower than for ECMWF data at the same location. Results differ to an even larger extent using average wind from the ECMWF model over the Channel and North Sea

The overall adjustment indices obtained with the recommended simulation parameters are given in Table 6 . This table also presents the adjustment results with values close to the recommended wind power factor (0.48). These results reveal the sensitivity of adjustment with this parameter. The radionuclide quantity balance (columns $3-5$ ) varies by $4 \%$ for wind power factor differences of 0.02 , while the correlation indices are almost the same.

The mean fluxes through the Dover Strait $\left(126,564 \mathrm{~m}^{3} \cdot \mathrm{s}^{-1}\right)$ is slightly higher than the one deduced form radar measurements (Prandle et al, 1996: 94,000 $\mathrm{m}^{3} . \mathrm{s}^{-1}$ ), in the range obtained previously from modelling by Salomon et al (1993, 97,000 - 195,000 $\left.\mathrm{m}^{3} \cdot \mathrm{s}^{-1}\right)$, and very close from the mean flux obtained from radionuclides measurements between January and July 1988 (Bailly du Bois et al, 1993, 130,000 $\mathrm{m}^{3} \cdot \mathrm{s}^{-1}$ ).

Figure 15 and Figure 16 show the maps of the concentration distributions measured and computed for each survey with the recommended parameters.

\begin{tabular}{|c|c|c|c|c|c|c|c|c|c|c|c|c|}
\hline \multirow{3}{*}{$\begin{array}{l}\text { Minimum } \\
\text { diffusion } \\
\text { coefficient }\end{array}$} & \multirow{3}{*}{$\begin{array}{l}\text { Wind } \\
\text { power } \\
\text { factor } \\
\text { for } C_{d}\end{array}$} & \multirow{2}{*}{\multicolumn{3}{|c|}{$\begin{array}{l}\text { QV } \\
\text { Quantitative variation for } \\
\text { the six main surveys }\end{array}$}} & \multicolumn{3}{|c|}{ Individual measurements } & \multicolumn{2}{|c|}{$\begin{array}{c}\text { Mean } \\
\text { distribution }\end{array}$} & \multirow{3}{*}{\begin{tabular}{|c|} 
MF \\
Mean flux \\
through \\
the Dover \\
Strait \\
$\left(\mathrm{m}^{3} \cdot \mathrm{s}^{-1}\right)$ \\
\end{tabular}} & \multicolumn{2}{|c|}{$\begin{array}{l}\text { Mean wind } \\
\text { stress }\end{array}$} \\
\hline & & & & & \multirow{2}{*}{$\begin{array}{l}\text { CC } \\
\text { Correl. } \\
\text { Coef. }\end{array}$} & \multirow{2}{*}{\begin{tabular}{c|} 
MV \\
Mean \\
Variation
\end{tabular}} & \multirow{2}{*}{$\begin{array}{c}\text { P95 } \\
\text { Percent. } \\
\text { 95\% ratio } \\
\text { Meas/Sim }\end{array}$} & \multirow{2}{*}{$\begin{array}{l}\text { DM } \\
\text { Diff. } \\
\text { mean } \\
\text { conc. }\end{array}$} & \multirow{2}{*}{$\begin{array}{l}\text { MS } \\
\text { Mean } \\
\text { square } \\
\text { diff. }\end{array}$} & & \multirow{2}{*}{$\begin{array}{c}\text { Value } \\
\left(\mathrm{N} \cdot \mathrm{m}^{-2}\right)\end{array}$} & \multirow[b]{2}{*}{ Dir. } \\
\hline & & $\begin{array}{c}\text { Whole } \\
\text { area }\end{array}$ & $\begin{array}{l}\text { North } \\
\text { Sea }\end{array}$ & $\begin{array}{l}\text { English } \\
\text { Channel }\end{array}$ & & & & & & & & \\
\hline $50 \mathrm{~m}^{2} \cdot \mathrm{s}^{-1}$ & 0.46 & $4 \%$ & $5 \%$ & $2 \%$ & 0.882 & $55 \%$ & 3.43 & $6 \%$ & 11 & 122875 & 0.123 & $247^{\circ}$ \\
\hline $50 \mathrm{~m}^{2} \cdot \mathrm{s}^{-1}$ & 48 & $-0 \%$ & $-0 \%$ & 0\% & 0.879 & $54 \%$ & 3.60 & $3 \%$ & 11 & 126564 & 0.129 & $247^{\circ}$ \\
\hline $50 \mathrm{~m}^{2} \cdot \mathrm{s}^{-1}$ & 0.50 & $-4 \%$ & $-5 \%$ & $-2 \%$ & 0.877 & $54 \%$ & 3.63 & $-1 \%$ & 11 & 130448 & 0.136 & $247^{\circ}$ \\
\hline
\end{tabular}

Table $6 \quad$ Indices of the model/measurements comparison during adjustment of the recommended parameters (in bold)

\begin{tabular}{|c|c|c|c|c|c|c|c|c|c|c|c|c|}
\hline \multirow{3}{*}{$\begin{array}{c}\text { Minimum } \\
\text { diffusion } \\
\text { coefficient }\end{array}$} & \multirow{3}{*}{$\begin{array}{l}\text { Wind } \\
\text { power } \\
\text { factor } \\
\text { for } C_{d}\end{array}$} & \multirow{2}{*}{\multicolumn{3}{|c|}{$\begin{array}{c}\text { QF } \\
\text { Quantitative variation for } \\
\text { the six main surveys }\end{array}$}} & \multicolumn{3}{|c|}{ Individual measurements } & \multicolumn{2}{|c|}{$\begin{array}{c}\text { Mean } \\
\text { distribution }\end{array}$} & \multirow{3}{*}{\begin{tabular}{|c|} 
MF \\
Mean flux \\
through \\
the Dover \\
Strait \\
$\left(\mathrm{m}^{3} \cdot \mathrm{s}^{-1}\right)$ \\
\end{tabular}} & \multicolumn{2}{|c|}{$\begin{array}{l}\text { Mean wind } \\
\text { stress }\end{array}$} \\
\hline & & & & & \multirow{2}{*}{$\begin{array}{l}\text { CC } \\
\text { Correl. } \\
\text { Coef. }\end{array}$} & \multirow{2}{*}{$\begin{array}{c}\text { MV } \\
\text { Mean } \\
\text { Variation }\end{array}$} & \multirow{2}{*}{$\begin{array}{c}\text { P95 } \\
\text { Percent. } \\
\text { 95\% ratio } \\
\text { Meas/Sim }\end{array}$} & \multirow{2}{*}{$\begin{array}{l}\text { DM } \\
\text { Diff. } \\
\text { Mean } \\
\text { conc. }\end{array}$} & \multirow{2}{*}{$\begin{array}{l}\text { MS } \\
\text { Mean } \\
\text { square } \\
\text { diff. }\end{array}$} & & \multirow{2}{*}{$\begin{array}{l}\text { Value } \\
\left(\mathrm{N} . \mathrm{m}^{-2}\right)\end{array}$} & \multirow[b]{2}{*}{ Dir. } \\
\hline & & $\begin{array}{c}\text { Whole } \\
\text { area }\end{array}$ & $\begin{array}{l}\text { North } \\
\text { Sea }\end{array}$ & $\begin{array}{l}\text { English } \\
\text { Channel }\end{array}$ & & & & & & & & \\
\hline $50 \mathrm{~m}^{2} \cdot \mathrm{s}^{-1}$ & 0.48 & $1 \%$ & $-6 \%$ & $17 \%$ & 0.839 & $64 \%$ & 4.41 & $6 \%$ & 14 & 115131 & 0.119 & $250^{\circ}$ \\
\hline
\end{tabular}

Table $7 \quad$ Indices of the model/measurements comparison with the recommended parameters and Goury semaphore wind data (location $49^{\circ} 44^{\prime} \mathrm{N}, 1^{\circ} 58^{\prime} \mathrm{W}$ ) 


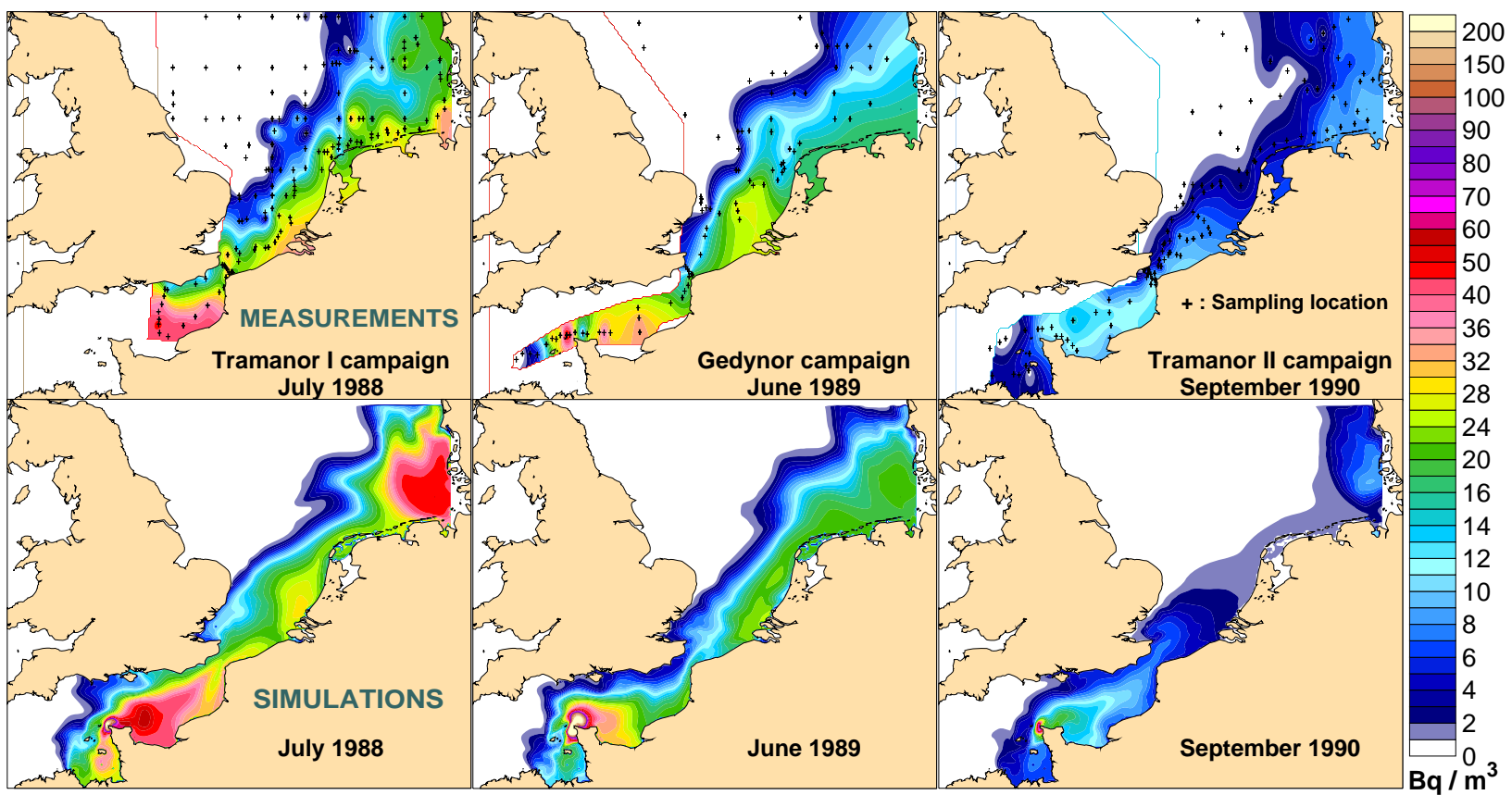

Figure 15 Comparison of measurements/simulation of the distribution of dissolved antimony 125 in the Channel and North Sea between 1988 and 1990, with the recommended parameters.

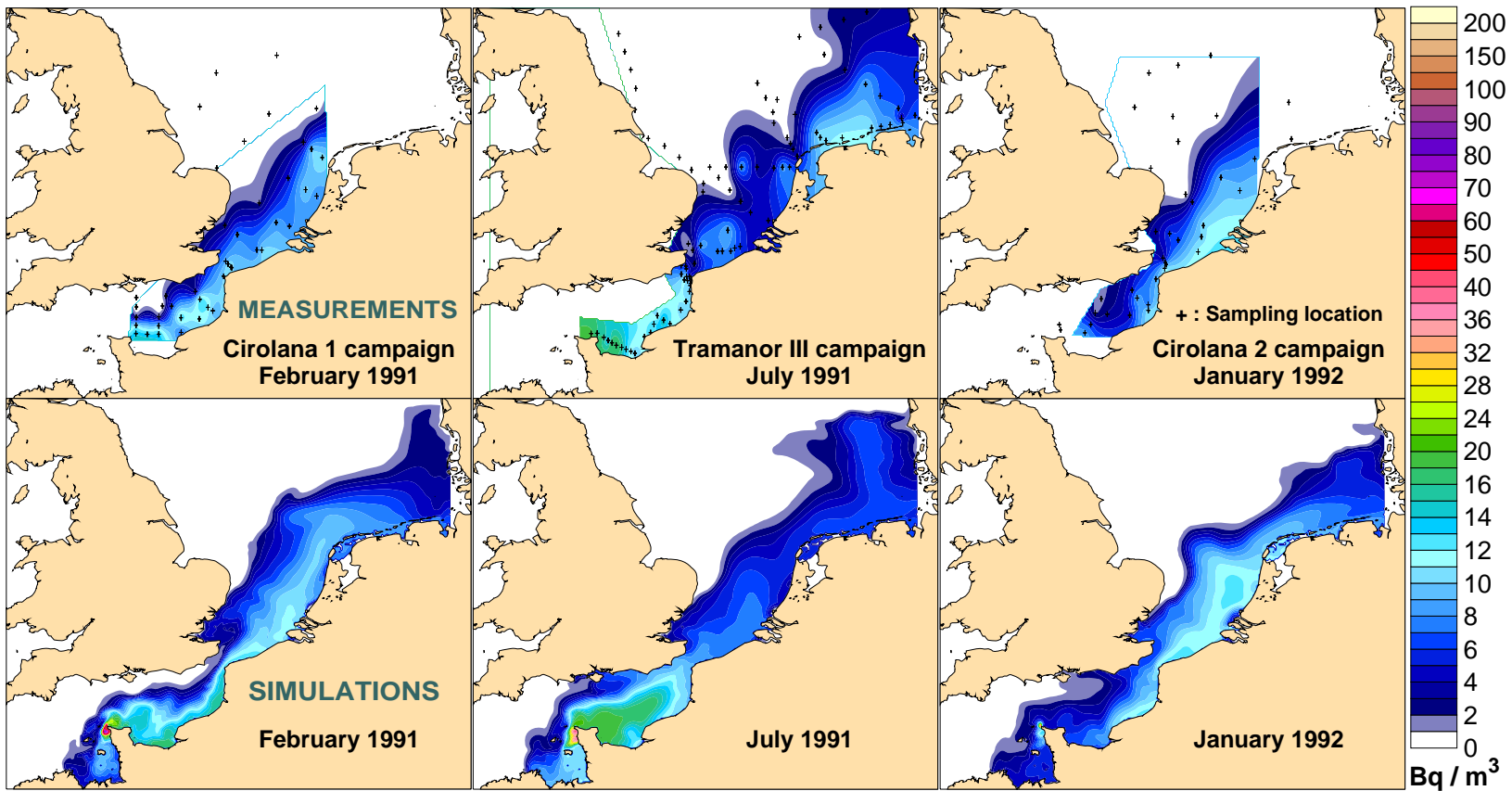

Figure 16 Comparison of measurements/simulation of the distribution of dissolved antimony-125 in the Channel and North Sea between 1991 and 1992, with the recommended parameters.

\subsubsection{Comparison of spot values}

The validation process only concerned the indices presented in section 3.5. This section presents a more detailed analysis of results obtained with the recommended parameters.

Figure 17 shows the simulated concentrations as a function of those measured for all the measurements used for validation. It shows that the simulated values for the highest concentrations are overestimated, which matches the findings of the earliest surveys. This trend is confirmed by the way differences evolve over time (Figure 18). 


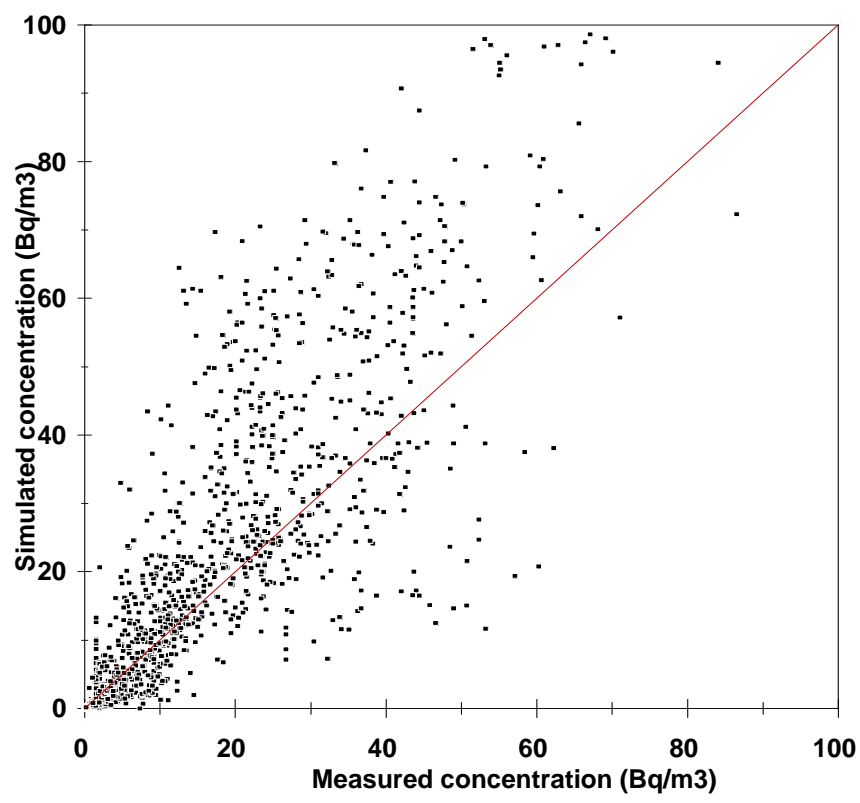

Figure 17 Concentrations measured as a function of simulated concentrations

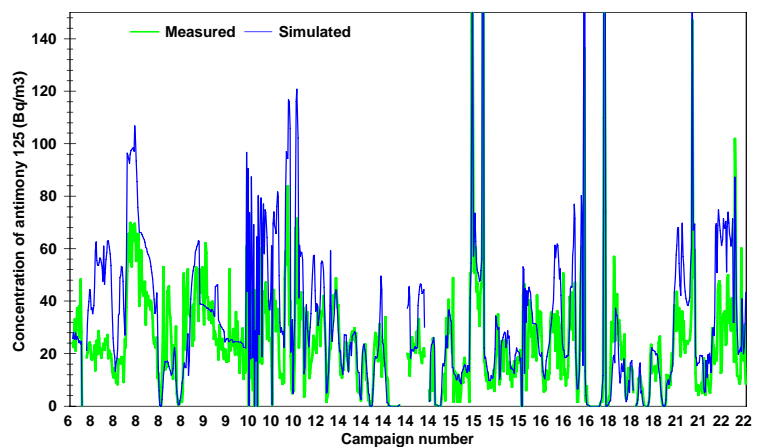

a

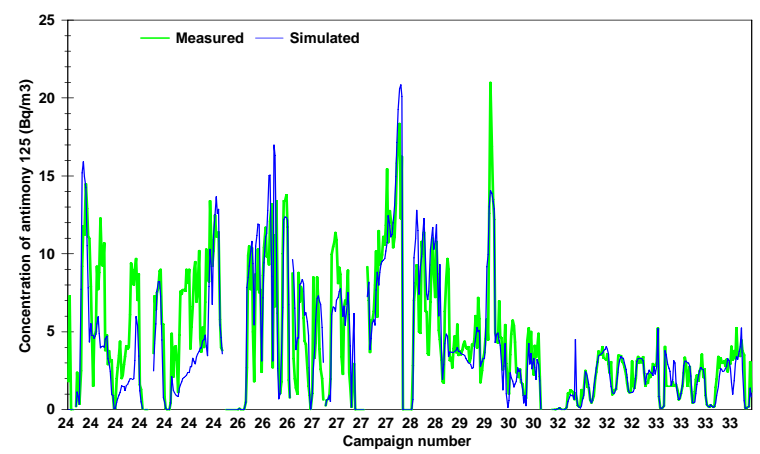

$\mathrm{b}$

Figure 18 Comparisons between calculated and measured concentrations for each sample during the surveys conducted from 1987 to 1989 (a) and from 1990 to 1994 (b)

In order to take this difference into account, the measured and simulated concentrations were divided by the release performed during the three months preceding each date of campaign. The distribution obtained Figure 19 does not show anymore significant underestimation/overestimation, the correlation line slope obtained is 1.01 .

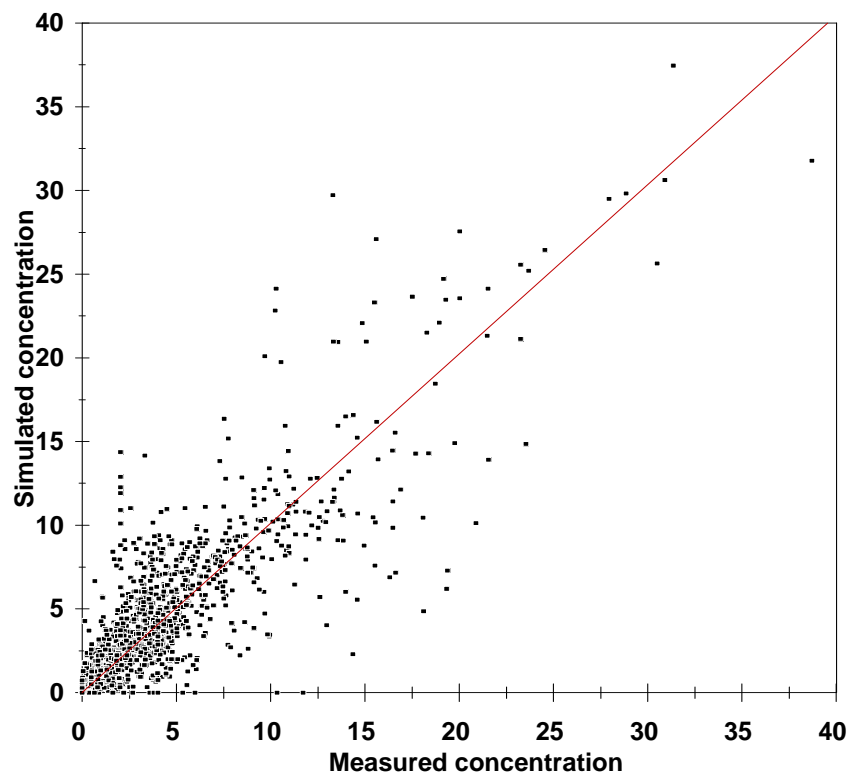

Figure 19 Concentrations measured as a function of simulated concentrations normalized by the release performed during the three months preceding each date of campaign $\left(\mathrm{Bq} / \mathrm{m}^{3} / 10^{12} \mathrm{~Bq}\right.$ released) 
The test value used to compare calculated and measured concentrations is the ratio between the calculated and measured values. In order to obtain a distribution centred on zero, the ratio ( $\left.\mathrm{R}_{\text {cent }}\right)$ was calculated as follows:

- When the calculated value is higher than the simulated value:

$$
\begin{aligned}
R_{c} & =\left(\frac{\text { SimConc }}{\text { MeasConc }}\right)-1 \\
R_{c} & =\left(\frac{- \text { MeasConc }}{\text { SimConc }}\right)+1
\end{aligned}
$$

- When the calculated value is lower than the simulated value:

SimConc: simulated concentration.

MeasConc: measured concentration.

Figure 20 shows $R_{c}$ as a function of the distance. This demonstrates that the model's representativeness is not significantly deteriorated after several months or years of dispersion. The greatest differences appear close to the source term in the Normand-Breton gulf. These deviations can be explained by much larger concentration gradients near the outlet point, particularly in the Normand-Breton gulf. This point is in close contact with Atlantic waters, which are not marked with ${ }^{125} \mathrm{Sb}$.

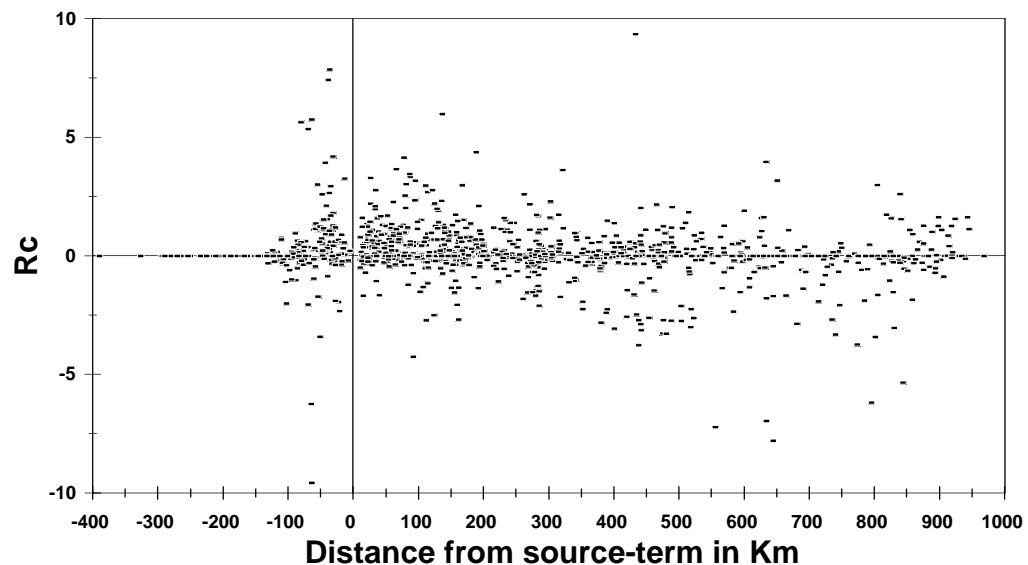

Figure 20 Ratio between calculated and measured concentrations as a function of distance from the outlet point, 1987 - 1994.

Figure 21a show $R_{c}$ distribution for all the values used for validation. The distribution is practically symmetrical, which shows that the model overestimates or underestimates the concentrations in the same proportions (average $R_{c}=0.11$ ). As the main calibration parameter is the equilibrium between measured and simulated quantities, this result is not surprising. It can be compared with the validation performed in 1995 by M. Breton and J.C. Salomon (Breton and Salomon, 1995) using an earlier version of the residual model. The distribution thus obtained (Figure 21 b) was clearly asymmetrical, which expresses an average overestimation of concentrations obtained by the model of about $100 \%$. To explain this asymmetry, the authors hypothesised that a significant fraction of ${ }^{125} \mathrm{Sb}$ could leave the water mass by fixing on living species and sediments. In this case the meteorological forcing applied was much lower.

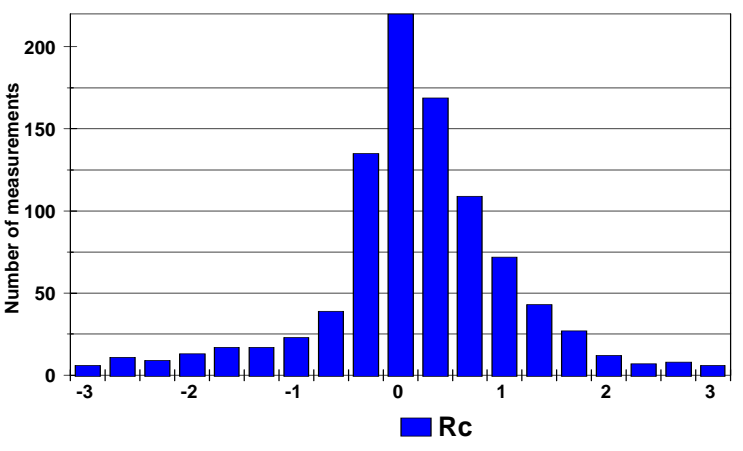

a

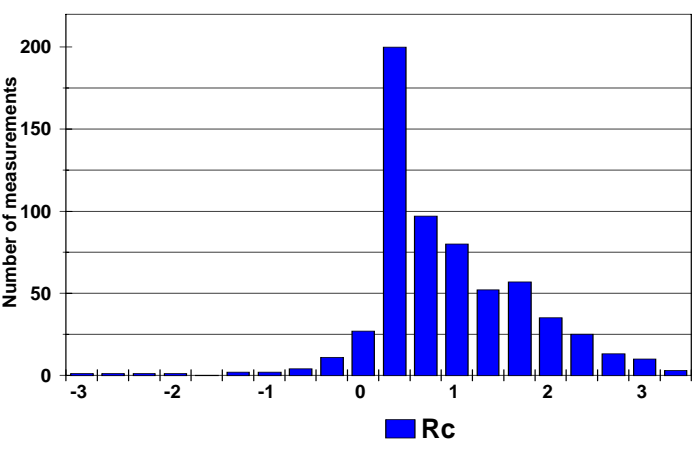

b

Figure 21 Comparison between distributions obtained during present validation (a) and that obtained by Breton and Salomon $(1995, b)$

Since a symmetrical distribution is obtained, this means that the ratio $\frac{\text { SimConc }}{\text { MeasConc }}$ is comparable to the ratio

$\frac{\text { MeasConc }}{\text { SimConc }}$ thus making it possible to simplify the distribution by representing it using the following formula III defined in §3.5: $\mathrm{R}=$ Maximum $\left[\left(\frac{\text { SimConc }}{\text { MeasConc }}\right)\right.$, ( $\left.\left.\frac{\text { MeasConc }}{\text { SimConc }}\right)\right]$ 
The corresponding percentile computation is given in Table 8; it shows that for $50 \%$ of measurements, the ratio between measured and calculated concentrations is less than 1.27. The extreme value shows that a difference higher than a factor of twelve is never reached.

\begin{tabular}{|c|c|c|c|c|c|c|c|}
\hline Percentile & $50 \%$ & $70 \%$ & $90 \%$ & $95 \%$ & $99 \%$ & $99.9 \%$ & $99.99 \%$ \\
\hline $\mathrm{R}_{\mathrm{m}}$ & 1.27 & 1.63 & 2.65 & 3.60 & 6.47 & 10.51 & 11.77 \\
\hline
\end{tabular}

Table $8 \quad$ Percentiles of the ratio between measured and calculated concentrations

\subsubsection{Comparison in average situation}

Figure 22 gives the standardised distribution of antimony-125 for a release of $10^{6} \mathrm{~Bq} \cdot \mathrm{s}^{-1}$, computed using measurements or taken from the model. Because they are close, the difference between the two distributions 100x(SimConc-MesConc) was computed as shown in Figure 23. MesConc

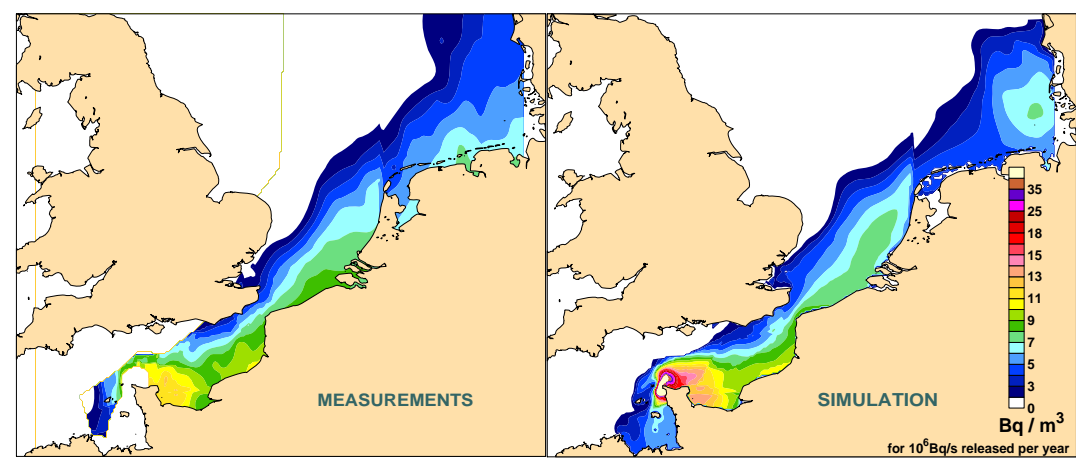

Figure 22 Average measured and simulated distribution of antimony-125 between 1988 and 1992, standardised for a release of $10^{6} \mathrm{~Bq} / \mathrm{s}$

On average, the differences between simulated and measured concentrations are below 20\%. The zones where the model overestimates concentrations are located northeast of the Cotentin peninsula, in the Thames river plume and in the German Bight. The latter anomaly is mainly due to measurements taken during the oldest survey (1988). This is probably because the applied wind, coming from the centre of the Channel, is not sufficiently representative. However, the maximum mean difference in this zone does not exceed $30 \%$, which remains a reasonable value for concentrations computed $800 \mathrm{~km}$ from the outlet point.

The areas where the model underestimates the concentrations are more scattered. Most of them appear to the west of the Cotentin peninsula and in the western part of the German Bight. The minimum anomaly on the model's northern boundary off Denmark is only due to the edge effect: the marked seawater which has left the model is lost. Should wind variations bring it back into the domain of the model, the model is incapable of acknowledging it.

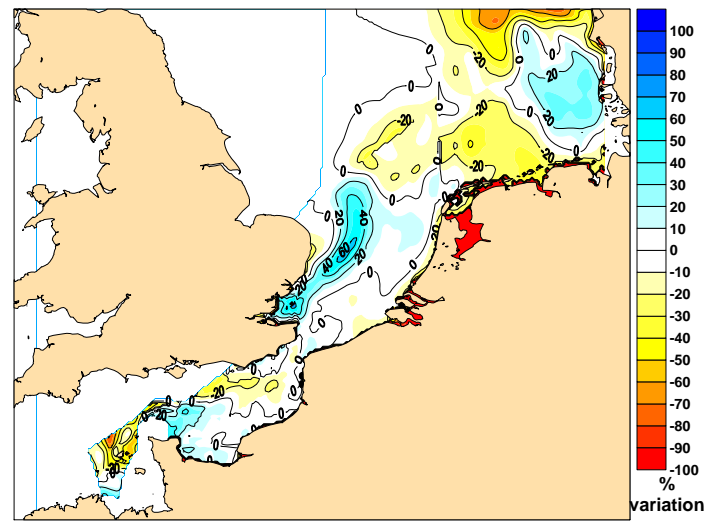

Figure 23 Difference in percentage between mean calculated and measured concentrations 100x(ConcSim-ConcMes)

\subsection{COMPARING MODEL/MEASUREMENTS, OTHER RADIONUCLIDES AND OTHER SURVEYS}

The model was considered to be validated using only antimony-125 measurements. For this reason, it was useful to compare the measurements of other radionuclides and more recent surveys to determine how representative the model was for data other than those used to calibrate it. 
Available data included both caesium-137, a radionuclide measured at the same time as antimony, but which is less conservative, and more recent surveys which were not assimilated in the validation process. These particularly concern measurements of tritium, which is a strictly conservative tracer in seawater in the form of HTO.

For the conservative radionuclides, maps of simulated and measured distributions are given in Figure 24 for ${ }^{125} \mathrm{Sb}$ and Figure 25 for ${ }^{3} \mathrm{H}$. The measured distribution maps for these two radionuclides are very close to the simulated maps, and the agreement appears to be rather better than with the measurements used for validation. The comparison between measured and simulated concentrations for ${ }^{125}$ Sb between April 1994 and December 1994 (Figure 24) gives a correlation coefficient of 0.897 and $R_{m}$ of 2.6 for a 95\% percentile. Theses values are significantly better than the ones obtained from previous campaigns (0.879 and 3.6 respectively). The better agreement could be due to improvement in the ECMWF model over time. Overall, the differences observed have same order of magnitude as errors which could be due to measurements or to the interpolation process.

The main difference appears for tritium measured off Fécamp and more generally along the Pays de Caux coast with a maximum concentration of $6000 \mathrm{~Bq} \cdot \mathrm{m}^{-3}$ (Figure 25). These differences can be explained by La Hague labelling being diluted by the Seine river plume, whose concentrations during the simulation were nil. The few measurements obtained in the Seine showed concentrations varying from 3,000 to 9,000 Bq/ $\mathrm{m}^{3}$. Therefore, it is plausible that the Seine marking could explain the concentrations measured. Releases from the Paluel and Penly power plants could also contribute to the labelling. Available data do not make it possible to quantify the respective influences of the Seine and these releases.

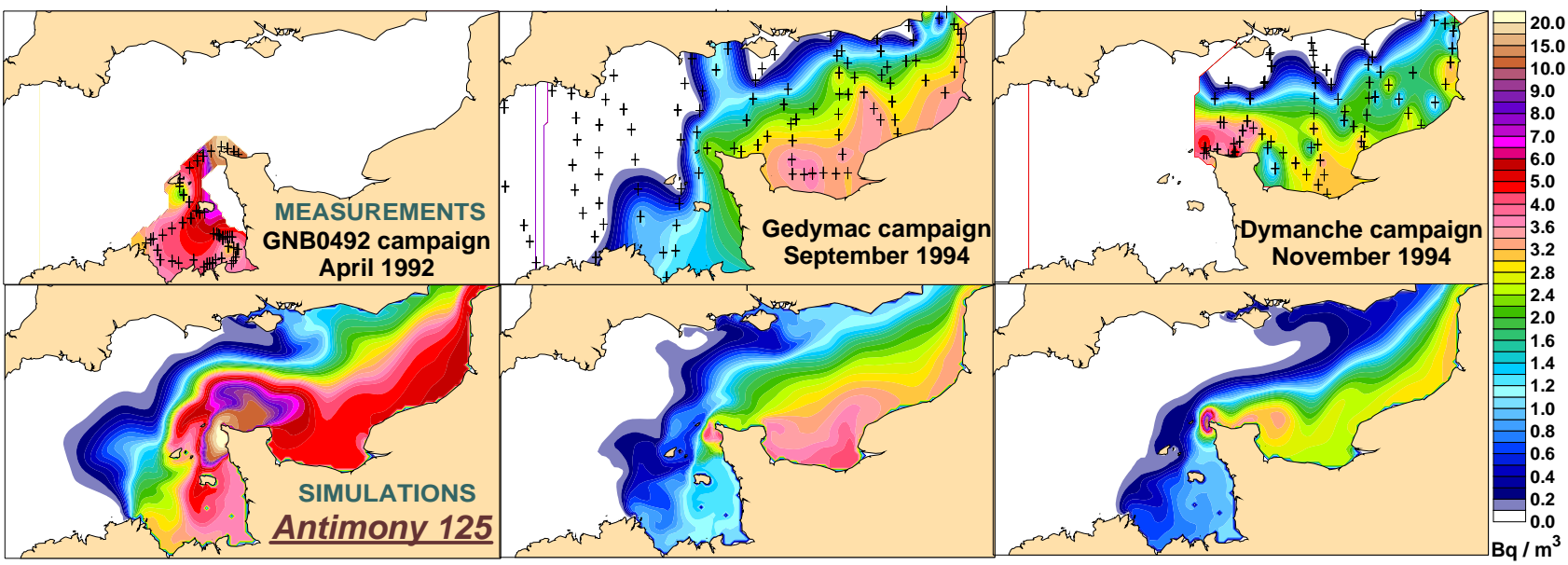

Figure $24 \quad$ Simulated and measured distribution of antimony-125 in 1992 and 1994

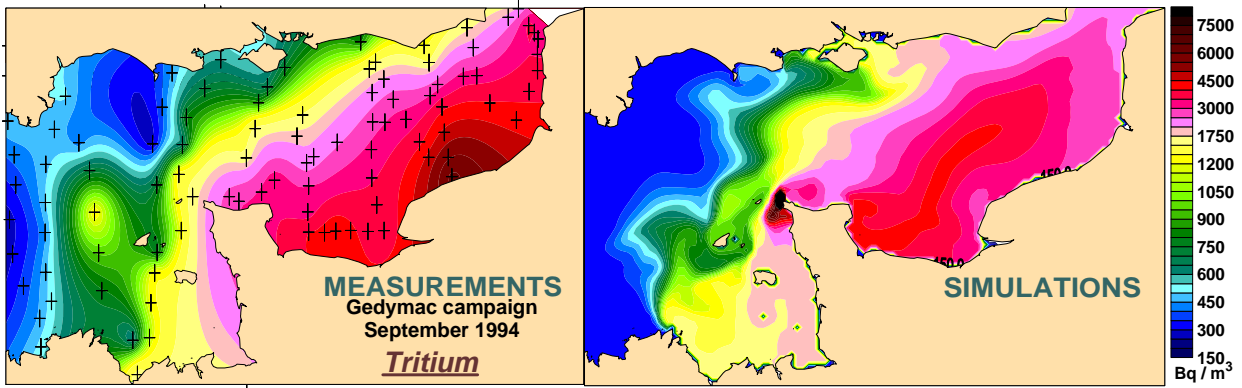

Figure $25 \quad$ Simulated and measured distribution of tritium in September 1994

For ${ }^{137} \mathrm{Cs}$ (Figure 26), the simulated concentrations are logically lower than those measured, which is consistent with earlier studies which evaluated the rate of loss of soluble caesium in the Channel to be approximately $20 \%$ (Bailly du Bois et al., 1999). However, the dispersion structures are well reproduced by the model, particularly in 1994, when releases significantly above average began in September 1994. Although the concentrations were lower, the simulation provides spatial distribution of the plume which is similar to that obtained from measurements. 


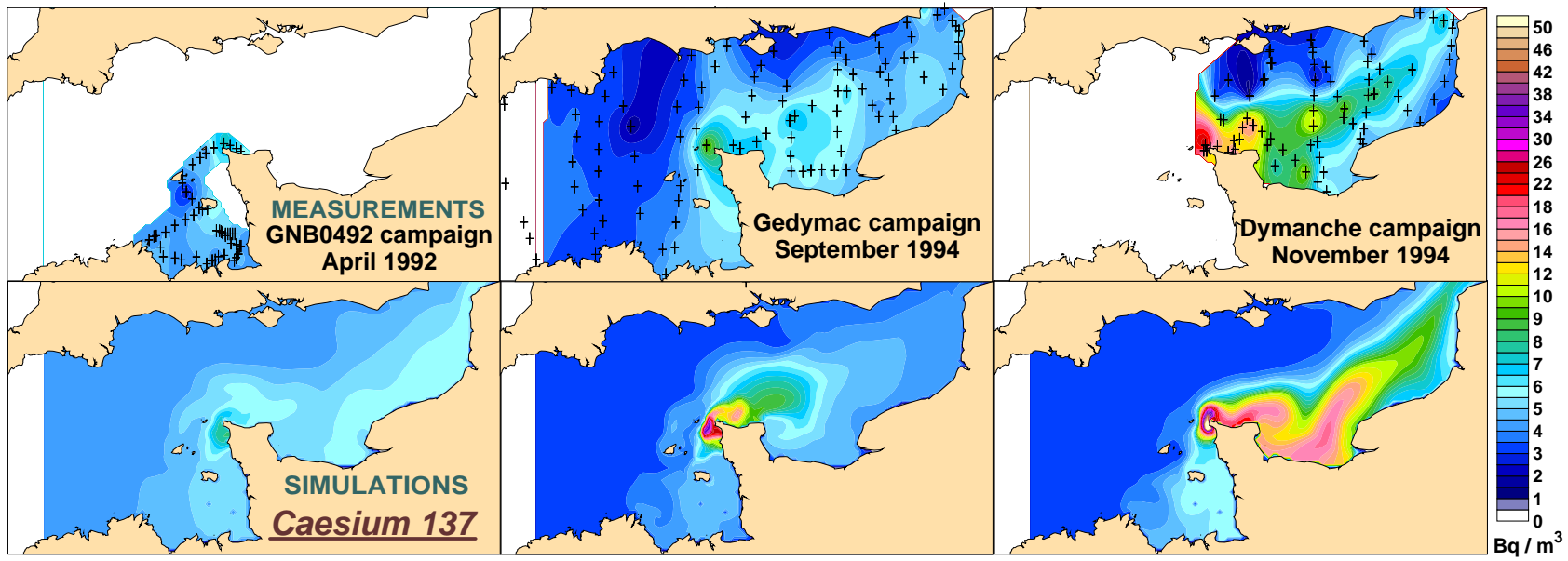

Figure 26

Simulated and measured distribution of caesium-137 in 1992 and 1994

\section{CONCLUSION}

A hydrodynamic model has been developed by applying methods perfected by Salomon and Orbi (1988). It was designed to realistically simulate the dispersion and transfer of soluble substances in the marine environment at a low computation cost. This 2D model must recreate and predict rapidly the consequences of chronic or accidental releases of radionuclides or other soluble substances, whether from point or non-point sources (nuclear facilities, shipping accidents, atmospheric fallout). Its domain covers the entire English Channel and the southern North Sea, and from Brittany's Atlantic coastline to Denmark. The model could be used at a distance of more than $30 \mathrm{~km}$, and from one week after a release from the outflow point, during several years with short computing times (less than one hour for a one year simulation). Due to 2D approximations, it could only reproduce releases from outlet located in well-mixed areas (eastern English Channel, south North Sea and coastal zones).

The possible uses of such model depend directly on its degree of reliability as demonstrated by its validation. So a great effort was devoted for this purpose. This validation was based on a database containing 1,400 measurements of a conservative radionuclide, antimony-125, repetitively covering all of the English Channel and the North Sea. This tracer has a single significant source in the studied area, i.e. the nuclear fuel reprocessing plant at La Hague. The flows discharged have been identified for each release since 1982.

Over one thousand simulations, each covering nine years, were performed in order to test the main parameters possibly involved in dispersion mechanisms in seawater. The validation was based on conventional quality criteria (correlation coefficients) as well as quantitative comparisons between stocks of simulated radionuclides and those measured during various oceanographic surveys.

Compilation of these simulations showed that the two main adjustment parameters used to make the computed and simulated concentrations correspond were:

- the frictional force induced by the wind on the sea surface;

- the origin and location of wind data used.

Whatever the wind data used, the balance between the quantities of radionuclides measured and those calculated could only be obtained by considerably increasing the wind stress. The drag coefficient obtained is equal to $C_{d}=0.0015 x\|\overrightarrow{\mathrm{W}}\|^{0.48} \mathrm{~m}^{2} \cdot \mathrm{s}^{-1}$ where $\|\overrightarrow{\mathrm{W}}\|$ is the wind vector module. With the climatologies observed, this coefficient means multiplying the average computed wind stress by 2.5 , with $\mathrm{C}_{\mathrm{d}}=0.0015$.

The data set and type of model used enable comparisons between the simulated and computed data over large time and space scales that are not usually accessible for testing wind stress computation formulae. This can explain in part the significance of wind-induced forcing with respect to the conventional wind stress computation formulae used.

The analysis and use of several sets of wind data showed that the origin of the wind speed taken into account (models, observations) could make the long-term movement of water masses vary considerably. The data from the European ECMWF meteorological model were selected because of their spatial-temporal coverage and homogeneity. However, it seems that these data lead to a significant underestimation of the frictional stress induced on the sea. 
The model can still be improved. In future, it will be necessary to determine whether a tidally resolving model taking better account of all the phenomena (real wind fields, atmospheric pressure gradients) requires the application of such a high drag coefficient.

With the validation parameters that were chosen, the correspondence between simulation results and measurements is as follows:

- The overall quantities of radionuclides calculated and measured over the six sampling surveys carried out from 1988 to 1994 are balanced out to $\pm 1 \%$, both over the entire dispersion area of the Channel and the North Sea and on each of these seas taken separately;

- The correlation coefficient between all 1,400 concentrations measured and the concentrations computed for the same places and dates is close to 0.88;

- The mean difference between the individual values calculated and measured is 54\%;

- For half of the 1,400 measurements, the ratio between the measured and calculated concentrations is under 1.27. This ratio was less than $3.6 \%$ for $95 \%$ of measurements and never exceeded a factor of 12 ;

- comparison with more recent measurement results, which were not taken into account in the validation data sets, show agreement at least equivalent to that obtained with the data used to validate the model;

- The differences between the computed and measured values are comparable at $30 \mathrm{~km}$ or 1,000 km from the outlet point.

The mean flux through the Dover Strait is $126000 \mathrm{~m}^{3} . \mathrm{s}^{-1}$, close to the one obtained from previous studies (Salomon et al, 1993, Bailly du Bois et al, 1995, Prandle et al, 1996).

It should be remembered that the uncertainty obtained includes errors involving the measurement of soluble radionuclides. This error varies from $5 \%$ to $50 \%$ for all of the field data used and the average error can be estimated at $15 \%$. Given these uncertainties, it would probably be difficult to obtain a greatly improved agreement between simulated and measured results with this type of data.

Despite the simplifications induced by the method and the empirical adjustment performed, the model appears to be robust in view of the wide range of tests performed and the agreement obtained between computed and simulated results. This means that computational modules can be added for transfers radionuclides towards living species and sediments in the marine environment in order to estimate concentrations induced by radionuclides releases in realistic situations. This has been done by calculation of concentrations induced in living species and sediments by applying kinetics and concentration factors at each time step and for each mesh of the hydrodynamic model. This method is described in (Bailly du Bois, 2003), it allow a significant assessment of transfer kinetics towards living species (Fiévet and Plet, 2002).

\section{ACKNOWLEDGEMENTS}

We are particularly grateful to the scientific teams aboard during the various sea cruises (IRSN/LERFA, CEFAS/Lowestoft, University of Southampton, Groupe d'Etudes Atomiques de la Marine Nationale, Université de Brest - CNRS Brest/Roscoff), and to the crews of the ocean research vessels, who enabled us to measure radioactivity as see since 1987 (the CNRS vessels "Pluteus II", "Côtes d'Aquitaine” and "Côtes de la Manche", IFREMER/GENAVIR vessels "Cryos", "Noroît” and "Suroît”, CEFAS vessel "Cirolana” and BSH vessel "Valdivia”). We would also like to thank our colleagues from LERFA, for allowing me free access to their personal computers for several years.

We appreciate the far-seeing comments from anonymous reviewers that allowed improving the manuscript.

\section{REFERENCES}

Amorocho, J. and de Vries, J.J. (1980) A new evaluation of the wind stress coefficient over water surfaces. Journal of Geophysical Research, C1(85), pp.434-442.

Arakawa, A. and Lamb, V.R. (1977) Computational design of the basic dynamical processes of the UCLA general circulation model. In: Methods in Computational Physics, Academic press, 17, pp.174-265.

Bailly du Bois, P., Guéguéniat, P., Gandon, R., Léon, R. and Baron, Y. (1993) Percentage contribution of inputs from the Atlantic, Irish Sea, English Channel and Baltic into the North Sea during 1988 : a tracer-based evaluation using artificial radionuclides. Netherlands Journal of Sea Research, 1(31), pp.1-17.

Bailly du Bois, P., Salomon, J.C., Gandon, R. and Guéguéniat, P. (1995) A quantitative estimate of English Channel water fluxes into the North Sea from 1987 to 1992 based on radiotracer distribution. Journal of Marine Systems, 6(5-6), pp.457-481.

Bailly du Bois, P., Rozet, M., Thoral, K. and Salomon, J.C. (1997) Improving knowledge of water-mass circulation in the English Channel using radioactive tracers. In: Special issue "Radionuclides in the Oceans", RADOC 96-97, Proceedings Part 1 "Inventories, behaviour and processes" Cherbourg-Octeville (France), 7-11 October, 1996. P. Germain, J.C. Guary, P. Guéguéniat and H. Métivier, editors, Radioprotection - colloques, April 1997, 32(C2), pp.63-69. 
Bailly du Bois, P. and Guéguéniat, P. (1999) Quantitative assessment of dissolved radiotracers in the English Channel : sources, average impact of la Hague reprocessing plant and conservative behaviour (1983, 1986, 1988 and 1994). Continental Shelf Research ; FluxManche II dedicated volume, 19, pp.1977-2002.

Bailly du Bois, P. Germain P., Rozet, M. and Solier, L. (2002) Water masses circulation and residence time in the Celtic Sea and English Channel approaches, characterisation based on radionuclides labelling from industrial releases. In: Proceedings from the International Conference on Radioactivity in Environment, Monaco 1 - 5 September 2002, Per Borretzen, Torun Jolle and Peer Strand, editors, pp. 395 - 399.

Bailly du Bois, P. (2003) TRANSMER, modèle de simulation des transferts de radionucléides en Manche et Mer du Nord : choix des options, description, validation et fonctionnalités. Report IRSN/DPRE/SERNAT/2003-04, 188 pp.

Breton, M. and Salomon, J.C. (1995) A 2D long-term advection-dispersion model for the Channel and southern North Sea. Part A: validation through comparison with artificial radionuclides. Journal of Marine Systems, 6(5-6), pp.495-514.

Chabert d'Hières, G. and Le Provost, C. (1978) Atlas des composantes harmoniques de la marée dans la Manche. Annales Hydrographiques 6, pp.5-36.

Coelingh, J.P., van Wijk, A.JM. and Holtslag, A.A.M. (1996) Analysis of wind speed observations over the North Sea. Journal of Wind Engineering and Industrial Aerodynamics, 61, pp.51-69.

Coelingh, J.P., van Wijk, A.JM. and Holtslag, A.A.M. (1998) Analysis of wind speed observations on the North Sea coast. Journal of Wind Engineering and Industrial Aerodynamics, 73, pp.125-144.

Dahlgaard, H., Chen, Q. and Nielsen, S.P. (1991) Radioactive tracers in the Greenland sea. In : Radionuclides in the study of marine processes. Norwich, UK, 10-13 September 1991, Kershaw J.P. and Woodhead D.S. editors, Elsevier Applied Science, pp.12-22.

Elder, J.W. (1959) The dispersion of marked fluid in turbulent shear flow. Journal of Fluid Mechanics, 5(4) , pp.544-560.

Fiévet, B. and Plet, D. (2002) Estimating biological half-lives of radionuclides in marine compartments from environmental time-series measurements. Journal of Environmental Radioactivity, 65, pp.91-107.

Gandon, R. and Guéguéniat, P. (1992) Preconcentration of ${ }^{125} \mathrm{Sb}$ onto $\mathrm{MnO}^{2}$ from Seawater Samples for Gamma-ray Spectrometric Analysis. Radiochimica Acta, 57, pp.159-164.

Gandon, R., Bailly du Bois, P. and Baron, Y. (1998) Caractère conservatif de l'antimoine 125 dans les eaux marines soumises à l'influence des rejets de l'usine de retraitement des combustibles irradiés de La Hague. Radioprotection 33(4) , pp.457-482.

Garratt, J.R. (1977) Review of drag coefficients over oceans and continents. Monthly Weather Review, 10, pp.915-929.

Guéguéniat, P., Bailly du Bois, P., Gandon, R., Salomon, J.C., Baron, Y. and Léon, R. (1994) Spatial and Temporal distribution (1987-91) of 125Sb used to trace pathways and transit times of waters entering the North Sea from the English Channel. Estuarine, Coastal and Shelf Science, 39, pp.59-74.

Guéguéniat, P., Bailly du Bois, P. and Gandon, R. (1995) Estimation of La Hague contribution to the artificial radioactivity of Norwegian waters (1992-1996) and Barents sea (1992-1997). In : Environmental radioactivity in the Arctic. P. Strand and A. Cooke, editors, Osteras, pp.102107.

Guéguéniat, P., Bailly du Bois, P., Salomon, J.C., Masson, M. and Cabioch, L. (1995) Fluxmanche radiotracers measurements: A contribution to the dynamics of the English Channel and North Sea. Journal of Marine Systems, 6, pp.483-494.

Guéguéniat, P., Herrmann, J., Kershaw, P., Bailly du Bois, P. and Baron, Y. (1997) Artificial radioactivity in the English Channel and the North Sea. Radionuclides in the Oceans, inputs and inventories", RADOC 96-97, P. Guéguéniat, P. Germain, and H. Métivier, editors, Les Editions de Physique, pp.121-154.

Guéguéniat, P., Kershaw, P., Herrmann, J. and Bailly du Bois, P. (1997) New estimation of La Hague contribution to the artificial radioactivity of Norwegian waters (1992-1995) and Barents Sea (1992-1997). The Science of the Total Environment, 202, pp.249-266.

Heaps, N.S. (1965. Storm surges on a continental shelf. Philosophical Transactions of the Royal Society of London series A-Mathematics, 257, pp.351-383.

Herrmann, J., Kershaw, P.J., Bailly du Bois, P. and Guéguéniat, P. (1995) The distribution of artificial radionuclides in the English Channel, southern North Sea, Skagerrak and Kattegat, 1990-1993. Journal of Marine Systems, 6(5-6), pp.427-456.

Jones, I.S.F. and Toba, Y. (2001) Wind stress over the ocean. In: Atmospheric Research, Edgar L. Andreas, editor, Cambridge University Press ISBN 052166243 5, 2001, 307 pp.

Kautsky, H. (1988) Determination of distribution processes, transport routes and transport times in the North Sea and the northern north Atlantic using artificial radionuclides as tracers. In: Radionuclides: a tool for oceanography Cherbourg 1-5 June 1987, Guary J.C., Guéguéniat P., and Pentreath R.J., editors, Elsevier Applied Science Publishers, LONDON-NEW YORK, pp. 271-280.

Kershaw, P.J. and Baxter, A. (1995) The transfer of reprocessing wastes from north-west Europe to the Arctic. Deep Sea Research "Topical studies in oceanography : Arctic Radioactivity and Related Transport Processes" Part II, 42(6), pp.1413-1448 .

Manning, J. and Strout, G. (2001) Georges Bank Winds: 1975-1997. Deep Sea Research Part II: Topical Studies in Oceanography, 48(1-3), pp. 115-135.

Météo France (2001) Bulletin trimestriel de contrôle des produits numériques utilisés pour la prévision météorologique. Direction de la Prévision, Série Contrôles et Diagnostiques, n58 - Août 2001, 75pp.

Morin V. and Frédéric A. (2001) Possibilités d'exploitation des gisements naturels de Crassostrea gigas dans le département de la Manche. DESS report “Exploitation des Ressources Vivantes Côtières”, Université de Caen 2000-2001, 58pp.

Nies, H. and Wedekind, C. (1988) The contamination of the North Sea and Baltic Sea by the Tchernobyl fallout. In: Radionuclides: a tool for oceanography Cherbourg 1-5 June 1987, Guary J.C., Guéguéniat P., and Pentreath R.J., editors, Elsevier Applied Science Publishers, LONDON-NEW YORK, pp. 227-239.

Nihoul J.C.J. (1980) Residual circulation, long waves and mesoscale eddies in the North Sea. Océanologica Acta 3 (3), pp.309 - 316.

Orbi, A. and Salomon, J.C. (1988) Dynamique de marée dans le Golfe Normand-Breton . Océanologica Acta, 11(1), pp.55-64.

Okubo, A. (1971) Oceanic diffusion diagrams. Deep-Sea Research, 18, pp.789-802.

Okubo, A. (1974) Some speculations on oceanic diffusion diagrams. ICES, Rapports et Procès-Verbaux, 167, pp.77-85.

Povinec P.P., Bailly du Bois P., Kershaw P.J., Nies H., Scotto P. (2003) Temporal and spatial trends in the distribution of ${ }^{137}$ Cs in surface waters of Northern European Seas--a record of 40 years of investigations. Deep Sea Research Part II: Topical Studies in Oceanography, 50(17-21), pp.2785-2801.

Proctor, R. and Wolf, J. (1990) An investigation of the storm surge of February 1, 1983 using numerical model. Modelling Marine system, CRC Press, 1, pp.43-72.

Pingree R.D., Griffiths D.K. (1978) Tidal front on the Shelf Seas Around the British Isles. Journal of Geophysical research 20, pp.4615-4630. 
Prandle D., Ballard G., Flatt D., Harrison A.J., Jones S.E., Knight P.J., Loch S., McManus J., Player R., Tappin A. (1996) Combining modelling and monitoring to determine fluxes of water, dissolved and particulate metals through the Dover Strait. Continental Shelf Research, 16(2), pp.237-257.

Salomon, J.C., Guéguéniat, P., Orbi, A. and Baron, Y. (1988) A lagrangian model for long-term tidally induced transport and mixing. Verification by artificial radionuclide concentrations. In: Radionuclides: a tool for oceanography Cherbourg 1-5 June 1987, Guary J.C., Guéguéniat P., and Pentreath R.J., editors, Elsevier Applied Science Publishers, LONDON-NEW YORK, pp. 384-394.

Salomon, J.C., Guéguéniat, P. and Breton, M. (1991) Mathematical model of ${ }^{125} \mathrm{Sb}$ transport and dispersion in the Channel. In : Radionuclides in the study of marine processes, Norwich, UK, 10-13 September 1991, Kershaw J.P. and Woodhead D.S., editors, Elsevier Applied Science, pp. 74-83.

Salomon, J.C. and Breton, M. (1993) An atlas of long-term currents in the Channel. Oceanologica Acta, 16(5-6) , pp.439-448.

Salomon, J.C., Breton, M. and Guéguéniat, P. (1993) Computed residual flow through the Dover Strait. Oceanologica Acta, 16(5-6):449-455.

Salomon, J.C., Breton, M. and Guéguéniat, P. (1995) A 2D long-term advection-dispersion model for the Channel and southern North Sea. Part B: Transit and transfer function from Cap de La Hague. Journal of Marine Systems, 6(5-6), pp.515-528.

Schwiderski, E.W. (1983) Atlas of ocean tidal charts and maps, part 1: the semidiurnal principal lunar tide M2. Marine Geodesy, 6, pp.219-265.

Staneva, J.V. and Stanev, E.V. (1998) Oceanic response to atmospheric forcing derived from different climatic data sets. Intercomparison study for the Black Sea. Oceanologica Acta Volume, 21(3), pp.393-417.

Townsend, T. L., Hurlburt, H.E. and Hogan, P.J. (2000) Modeled Sverdrup flow in the North Atlantic from 11 different wind stress climatologies. Dynamics of Atmospheres and Oceans, 32(3-4), pp.373-417.

Wu, J. (1980) Wind-stress coefficients over sea surface near neutral conditions, a revisit. Journal of Physical Oceanography, 10, pp.727-740. 